\title{
Evolution of dispersal strategies in conifers: functional divergence and convergence in the morphology of diaspores
}

\author{
D.L. Contreras ${ }^{1,2}$, I.A.P. Duijnstee ${ }^{1,2}$, S. Ranks ${ }^{1}$, C.R. Marshall ${ }^{1,2}$, C.V. Looy ${ }^{1,2,3}$ \\ ${ }^{1}$ Department of Integrative Biology, University of California-Berkeley, 3060 Valley Life Sciences \\ Building, Berkeley, CA 94720-3140, USA \\ ${ }^{2}$ University of California Museum of Paleontology, 1101 Valley Life Sciences Building, Berkeley, \\ CA 94720-4780, USA \\ ${ }^{3}$ University and Jepson Herbaria, 1001 Valley Life Sciences Building, Berkeley, CA 94720- \\ 2465, USA.
}

Corresponding author: Dori L. Contreras, dorilynne@berkeley.edu; 1101 Valley Life Sciences Building, Berkeley, CA 94720-4780, USA; +1 510-642-1607

(C) 2016. This manuscript version is made available under the Elsevier user license http://www.elsevier.com/open-access/userlicense/1.0/ 


\section{ABSTRACT}

We provide an integrative view of the evolution of dispersal strategies in modern conifers, by characterizing and examining the phylogenetic distribution of diaspore functional morphotypes, diaspore structural compositions, seed coat modifications, and dispersal syndromes using the phylogeny of Leslie et al. (2012). We first classified diaspores into nine functional morphotypes, which represent overall dispersal strategies that encompass the multiple phases of dispersal. We mapped these morphotypes, the eight different structural compositions of diaspores, two types of seed coat modifications, and the four recognized dispersal vectors onto the phylogeny and used maximum parsimony and maximum likelihood to infer ancestral states and assess shifts in dispersal characteristics. We found that structural traits (diaspore composition and seed coat modifications) are more conserved than ecological traits (functional morphotype and dispersal vector/syndrome). Almost all diaspore functional morphotypes have multiple independent origins, with several instances of parallelism (using the same structures to generate a morphotype) within families, but generally functional convergence (using different structures to generate a morphotype) between families. Within extant conifer families, shifts in the dispersal syndrome occur most frequently with simultaneous shifts in both diaspore morphotype and composition. Shifts from winged wind-dispersed to fleshy animal-dispersed diaspores are infrequent and occur only in the direction from wind to animal dispersal. Shifts to gravity or water dispersal occur from both wind and animal dispersed diaspores, concurrent with the loss of dispersal structures from the diaspore. Within both wind and animal-dispersed syndromes, further shifts between functional morphotypes represent differentiation of overall dispersal strategies, and occur most frequently without corresponding changes in the structural composition of the diaspore. The recurrent evolution of distinct morphologies suggests that there 
are local adaptive maxima that balance tradeoffs in traits related to both transport and establishment, within developmental limitations. Overall, our results suggest that the ancestral diaspore type for all modern conifers consisted only of a seed. Conifers diversified in their dispersal strategies through seed coat modifications or by the incorporation of various parts of the seed cone into the diaspore, with the modern conifer families independently evolving their characteristic diaspore compositions. Almost all functional morphotypes were present prior to the Cenozoic in at least one lineage, with more recent shifts in morphotypes representing functional convergence or parallel evolution rather than ecological novelties.

Keywords: diaspore, seed dispersal, conifer evolution, morphology, convergence, ancestral state

\section{INTRODUCTION}

Dispersal is an important process that shapes ecological and evolutionary patterns, and accordingly it has been the focus of a large body of theoretical and empirical literature. The ability of plants to effectively disperse their progeny across a temporally or spatially heterogeneous landscape has profound effects on the geographic distribution of taxa (Ackwood et al., 1993; Dynesius and Jansson, 2000; Edwards and Westoby, 1996; Longton, 1992; Rumeu et al., 2014), influences range shifts in response to climate change (Clark et al., 1998; Davis and Shaw, 2001; Higgins and Richardson, 1999; Thuiller et al., 2008), controls gene flow and the genetic structure of populations (Bacles et al., 2006; Hamrick et al., 1993), and ultimately influences the potential for both speciation and extinction (Leimer and Norberg, 1997; Van Valen, 1971). Dispersal is a multi-phase process (pre-departure, departure, transience, and 
settlement; see Lehouck et al., 2012), and seed plants exhibit a wide array of adaptations that facilitate all phases of the dispersal of their seeds. The collection of adaptations resulting in the overall phenotype of the diaspore (the seed plus any additional dispersing structures) thus represents a multivariate dispersal "strategy," which presumably confers an evolutionary benefit and reflects tradeoffs between adaptations related to the various phases of dispersal (e.g., Alcántara and Rey, 2003; Levin et al., 1984; Manzaneda et al., 2009; Schupp, 1995). Different dispersal strategies are shaped by, and in turn shape, the ecological interactions and structure of communities (Levine and Murrell, 2003; McPeek and Holt, 1992; Nathan and Muller-Landau, 2000; Starrfelt and Kokko, 2012).

The transport phase of dispersal (departure plus transience) is an important driver of plant distributions, in that it controls the total possible spatial distribution of a subsequent generation. It is perhaps for this reason that studies of diaspore phenotypes have focused primarily on their relation to mechanisms of movement. The most widely used dispersal classification, dispersal syndromes, is based upon suites of diaspore characters that relate to the plant's primary dispersal vector: by wind, water, biota, or the plant itself (including simply gravity) (Howe and Smallwood, 1982; Van der Pijl, 1982). Respectively, these syndromes are referred to as anemochory, hydrochory, zoochory, and autochory (barochory). These broad categorizations are useful for understanding alternate selection regimes and coarse differences in local patterns of dispersal. Within a given syndrome, different morphologies represent further differences in seed dispersal patterns that relate to various ecological strategies, such as various wing morphologies (Green, 1980) and fruit shapes and sizes (Geldenhuys, 1992; Ridley, 1930). Given that movement of the seed from the parent plant to a potential germination site is only one component of the multiphase process of dispersal, dispersal syndromes alone fall short of explaining the 
multi-functionality and ecological importance of diaspores. In particular they fail to recognize that diaspores reflect adaptive tradeoffs related to the relative importance of the various phases in the overall dispersal strategies of taxa.

The relationship between diaspore morphology and dispersal strategies, including the distribution of dispersal syndromes between and within families, has been studied primarily in extant and fossil angiosperms (e.g., Bremer and Eriksson, 1992; Eriksson et al., 2000; Manchester and O'Leary, 2010; Ridley, 1930; Tiffney, 1986a, 1986b; Tiffney and Mazer, 1995; Van der Pijl, 1982; Xiang et al., 2014). In comparison, conifers have received relatively little attention (but see Benkman, 1995; Givnish, 1980; Herrera, 1989; Leslie et al., 2013a; Tiffney, 1986a; Tomback and Linhart, 1990), even though they also exhibit a variety of strategies for seed dispersal. Conifers comprise a major clade of seed plants that has existed for over 300 million years (Taylor et al., 2009), and this longevity provides an ideal model system for studying the evolution of dispersal. They have a large, yet computationally manageable number of extant taxa; their modern relationships are fairly well known (e.g., Leslie et al., 2012); and they occupy a wide range of habitats in tropical to boreal environments (Eckenwalder, 2009). Furthermore, there is a large theoretical and empirical foundation for the homology of coniferous reproductive structures (e.g., Escapa et al., 2008, 2013; Florin, 1951; Rothwell et al., 2011; Serbet et al., 2010). The latter is particularly important because adaptations for different dispersal methods are achieved through seed coat modifications or by incorporating various parts of the seed cone into the dispersal unit. Thus, analyzing dispersal structures within a phylogenetic framework can provide a novel consideration of adaptations that have shaped dispersal ecology in conifers, past and present. 
The distribution of broad dispersal syndromes across living conifer taxa has been studied in relation to breeding systems (Donoghue, 1989; Givnish, 1980; Leslie et al., 2013a), biogeographic distributions (e.g., Rumeu et al., 2014), and taxonomic diversity (Herrera, 1989; Leslie et al., 2013a). Notably, however, the morphology of conifer diaspores remains largely unstudied from an evolutionary perspective across the conifer tree of life (but see Leslie, 2011, for discussion of cone functional evolution). It is clear, for instance, that fleshy diaspores are not all constructed from the same structures or developmental processes (e.g., Englund et al., 2011; Florin, 1951, 1954; Tomlinson and Takaso, 2002), yet diaspores in separate families can have strikingly similar phenotypes. In these cases, the observed similarities may not be due to common ancestry. Such homoplasy has important implications from an evolutionary-ecological perspective, as distantly related taxa with similar diaspores point towards the repeated evolution and refinement of phenotypes that represent particularly effective dispersal strategies. Similar phenotypes can develop independently in different lineages by either modifying the same structures following the same developmental pathway (parallelism), or by modifying completely different structures to achieve a similar overall form (functional convergence). While both may indicate that taxa face similar ecological pressures (Losos, 2011), parallelisms may also result from genetic and developmental constraints on variation (Pearce, 2011; Wake et al., 2011), functional tradeoffs in development (Greene and Johnson, 1993), and optimization of energetic costs to the parent plant (Chapin et al., 1993).

The goal of our study was to conduct a comprehensive analysis of diaspores as they relate to different dispersal strategies across living conifers within a phylogenetic context. The four major aspects explored here are (1) diaspore composition - which tissues or structures are included in the dispersal unit, (2) seed coat modifications - whether the seed coat has prominent 
dispersal adaptations (3) diaspore functional morphology - the overall phenotype as it relates to functional aspects of the multiple phases of dispersal, and (4) dispersal syndrome - the primary vector responsible for the transport phase of dispersal. By studying both the underlying structural (1-2) and emergent ecological (3-4) characteristics of diaspores, we investigated four main questions: (1) What is the diversity and distribution of diaspore functional strategies, as inferred by functional morphology, in extant conifers? (2) To what extent are similar diaspore functional morphologies in extant conifers likely due to convergence or parallelism? (3) Are dispersal traits fairly conserved within lineages, and if so, what are the inferred ancestral states for dispersal syndromes, diaspore functional morphology, composition, and seed coat modifications? (4) What is the frequency and pattern of evolutionary transitions between diaspore functional morphologies and dispersal syndromes?

To answer these questions, we provide a classification of conifer diaspores based on functional morphology and structure in the broader context of primary seed dispersal syndromes. Using this classification, we explore the phylogenetic distribution of diaspore functional morphotypes, diaspore composition, seed coat modifications, and dispersal syndromes by mapping characters onto a phylogeny of extant conifer taxa. We use one of the most complete conifer phylogenies to date, produced by Leslie et al. (2012), based on nuclear and chloroplast genes and with fossil calibration of divergence times. This phylogeny includes all extant genera (and $\sim 80 \%$ of all species), thus comprising a comprehensive framework within which trait evolution can be traced across extant lineages. Our findings are compared to known fossil conifer diaspores, and the evolutionary and ecological implications are discussed. Considering the influence of dispersal on local, community, regional, and biome-level processes, we anticipate that understanding the phylogenetic distribution of diaspore functional morphologies, 
coupled with more in-depth studies of their dispersal potential or realized seed distributions, will provide a platform to further inform the evolutionary dynamics of conifer groups and their current and paleo-biogeographic distributions (e.g., Mill, 2003; Rumeu et al., 2014).

\section{METHODS}

\section{Terminology and morphological foundation}

The following sections provide explanations of the botanical terminology used throughout this paper, basic descriptions of the variation between families, and the morphological foundation relevant to the structural composition of diaspores.

\section{The structure of conifer ovuliferous cones}

Extant conifers bear their seeds on ovuliferous cones, which can be understood within an evolutionary framework by their similar underlying bauplan. Adaptive transitions and homology of conifer reproductive organs have long been a topic of discussion among plant morphologists and paleobotanists

(e.g., Bessey, 1902; Escapa et al., 2008, 2013; Florin, 1938-1945, 1951, 1954; Rothwell et al., 2011; Schulz and Stützel, 2007; Schweitzer, 1963; Serbet et al., 2010), and have received more recent attention from developmental (Farjon and Ortiz Garcia, 2003; Jagel, 2001; Restemeyer, 2002; Schulz et al., 2003; Takaso and Tomlinson, 1990, 1991,1992; Tomlinson, 1992) and molecular studies (Carlsbecker et al., 2013; Englund et al., 2011; Groth et al., 2011). Since the works of Florin (1951, 1954), conifer ovuliferous cones have been interpreted as compound strobili that are modified branch systems (but see also discussions in Escapa et al., 2008; Serbet et al., 2010). They consist of a central axis surrounded by bracts that each subtend an ovuliferous scale on which the ovules are borne. The bracts are interpreted as 
modified penultimate leaves, and the ovuliferous scales as reduced and flattened axillary shoot systems (Florin, 1951; Carlsbecker et al., 2013).

Extensive modification and specialization of the various components of ovuliferous cones have resulted in the remarkable morphological diversity of ovule-bearing structures found in extant conifer families (see Tomlinson and Takaso, 2002). Here we briefly describe the most widely accepted hypotheses for the homology of the ovulate cone and its parts among extant conifer families. In Pinaceae the ovuliferous scales enlarge throughout maturation to become the dominant components of the mature cone (Bessey, 1902; Takaso and Owens, 1995; Tomlinson and Takaso, 2002). In Cupressaceae ovuliferous scales are reduced to small lobes (Cunninghamia) or are morphologically indistinguishable and presumably fully reduced (Farjon and Ortiz Garcia, 2003; Takaso and Tomlinson, 1992). Instead, the bracts enlarge via intercalary growth to form the dominant component of the mature cones (Farjon, 2005; Tomlinson and Takaso, 2002). In Araucariaceae, each bract and ovuliferous scale pair is fused for most or all of their length (Escapa and Catalano, 2013; Stockey, 1982). Podocarpaceae have a wide range of cone modifications, but are most notable for having fleshy cone parts. In most taxa, the fertile bract(s) have an axillary appendage called an epimatium, a fleshy structure that bears the ovule and is thought to be homologous with the ovuliferous scale (Englund et al., 2011; Restemeyer, 2002; Tomlinson, 1992). The epimatium surrounds the mature seed partially or fully, and in most cases serves to invert the ovule for pollination via asymmetrical growth during early development (Restemeyer, 2002; Tomlinson, 1992). In some genera (e.g., Podocarpus, Dacrycarpus, Acmopyle), the cone axis and lower sterile bracts become fleshy and fuse, forming a receptacle (podocarpium) below the one (to few) fertile bract(s) (Mill et al., 2001; Restemeyer, 2002; Tomlinson, 1992). The Taxaceae are generally regarded to have highly reduced cones, to the extent of having only a single "terminal" ovule, small bracts, and no recognizable ovuliferous scale (Stützel and Röwekamp, 1999; Tomlinson and Takaso, 2002). As the seed matures, it becomes surrounded by a fleshy aril, a non-vascularized outgrowth that arises late in development from 
the base of the seed (Tomlinson and Takaso, 2002), and which has no known homologies to the other structures of the archetypal ovuliferous cone (Englund et al., 2011; Restemeyer 2002).

Here we use the terms bract and ovuliferous scale separately when referencing individual structures that are morphologically distinguishable. We use the term bract-scale complex to refer to the entire lateral ovule-bearing structure, consisting of a bract plus ovuliferous scale, which can remain separate or be fused to various extents. The term "cone scale" has been used inconsistently in the literature to refer to either or both of the bract and ovuliferous scale, as well as for each fertile or sterile element of the plesiomorphic dwarf shoot, and thus will not be used here. Furthermore, due to its unique morphology, we often retain the traditional term epimatium when referring to the axillary appendage of fertile bracts in Podocarpaceae, even though it is interpreted as an extensively modified ovuliferous scale.

\section{The structure of diaspores}

Conifer diaspores may consist of a single seed, or the seed(s) plus additional structures. These include one or a combination of several of the following structures: (1) extra tissue derived from the adaxial surface of the ovuliferous scale, (2) entire ovuliferous scale or epimatium, (3) bract(s), (4) aril, and (5) cone axis. In the case of dispersal of the seed only, the seed coat may have prominent modifications for dispersal. The two primary modifications are wings formed from the integument (maternal tissue that surrounds the megasporangium and becomes the seed coat; see Gifford and Foster, 1989; Sporne, 1965) and a well developed sarcotesta (outer fleshy layer of the integument). Some seeds lack pronounced modifications, but can vary in the hardness of their seed coat or in the density of tissues, however due to the lack of sufficient available information about anatomical modifications of seeds across conifer taxa, were not able to considered these characteristics here. 
Fleshy structures are produced by modification of the seed coat or various parts of the ovuliferous cone, or a combination thereof. Wings, however, are produced via three different pathways: (1) as outgrowths of the integument that develop and extend concurrently with seed maturation (e.g., Agathis australis; Owens et al., 1997); (2) from tissues derived from the adaxial surface of the ovuliferous scale, forming a thin strip of tissue that either grows over and attaches to the adaxial surface of the seed, or grows around the seed attaching via a thin circumferential strip of tissue (e.g., Pinus sylvestris; Sporne, 1965); or (3) from the bract-scale complex, forming as thin, papery outgrowths from the lateral edges of each bract-scale complex (e.g., Araucaria cunninghamii; Haines, 1983). In the latter case, the seed is embedded within the bract-scale complex by tissues from the ovuliferous scale (Burlingame, 1915; Haines, 1983).

\section{Fructoid: reclaiming fruit sensu lato}

The botanical term "fruit" sensu stricto is defined in such a way that it can only apply to angiosperms (a mature ovary containing the seed(s)). Botanists in the past chose to focus their definition on aspects that highlight homology within the angiosperms (although the actual composition of angiosperm tissues in fruits may vary in a non-homologous way; Herrera, 1989; Howe and Smallwood, 1982; Van der Pijl, 1982). However, the functional aspects of fleshy fruits in the zoochorous dispersal of seeds are of enormous ecological, life-history, and macroevolutionary significance, as recognized in the colloquial word "fruit" as it has been used in the English language to indicate edible plant parts since the late $12^{\text {th }}$ century (OED Online, 2015). Most importantly, the definition of "fruit s.s." fails to recognize that functional "fruits sensu lato" pre-date the angiosperm clade, and still widely exist outside it (Herrera, 1989; Tiffney, 1986a). This is notably illustrated by the wide range of "fruits" occurring throughout the 
conifer phylogeny as shown in this paper. Hence, we argue that within certain contexts, functional aspects should take precedence in the definition of "fruits" over cladistic considerations and systematic convenience for angiosperms. Nevertheless, we here preserve the term "fruit" for angiosperm fruit s.s., and propose the term "fructoid" for functional fruit s.l. - i.e. diaspores with fleshy and/or attractive structures that function to aid zoochorous dispersal, irrespective of the botanical affinity of its producer. Despite the much wider taxonomic inclusiveness of fructoids relative to fruits, in our definition, the botanical entity "fruits" is not quite a subset of "fructoids," since the former also includes non-fructoid angiosperm diaspores, such as samaras and achenes.

\section{Analysis}

Classification of diaspore functional morphotypes and dispersal syndromes

Conifer diaspores were categorized into functional morphotypes based upon similarity in overall phenotype as it relates to dispersal ecology. Factors considered include the aerodynamics of winged diaspores, the presence of tissues that are fleshy and/or contrastingly colored, the overall shape and size of the diaspore, and the position of dispersing structures relative to the seed itself. Our goal was for the morphotypes to broadly represent different dispersal strategies at a finer scale than categorizations by dispersal vector (syndromes), yet generalized enough to be useful for recognizing functional equivalence in both extant and fossil diaspores. Because diaspore colors cannot be inferred from fossils, we did not incorporate them in the classification, despite their utility in delineating specific groups of animal dispersers (however, they are recorded in Table S1). Diaspore composition and the nature of seed coat modifications, as discussed under "The structure of diaspores," were not used in the delineation of functional morphotypes, but 
were incorporated into subcategories of the morphotypes to show the different structural means by which each morphotype is achieved. The structural subcategories for any one morphotype thus inherently represent functional convergence (i.e., compositional variation is here interpreted as homoplasy). We have adopted terminology from angiosperm fruit classifications in generating names for some of the categories based on their functional fructoid equivalence, rather than anatomical equivalence (Herrera, 1989), as well as the established use of such terms throughout conifer literature.

Primary dispersal syndromes were attributed to the morphotypes based upon functional characteristics of the diaspore and, where possible, published information on the dispersal vector for individual taxa (references in Table S1). Dispersal syndromes used here were anemochory, hydrochory, barochory, and zoochory. We did not account for mechanisms of secondary dispersal (after the initial movement away from the parent plant), although this has been shown to be an important contributor for the realized dispersal and distribution of some taxa (Vander Wall, 2008; Vander Wall et al., 2005). In this study, however, we are more interested in morphological adaptations, and we assume that natural selection on morphology is more strongly associated with primary dispersal, especially when the primary dispersal mechanism requires specific or costly adaptations (Herrera, 1989; Van der Pijl, 1982; Willson et al., 1990).

We did not differentiate between the various subcategories of zoochory, such as have been used by other researchers to delineate specific animal disperser groups (e.g., saurochory, ornithochory, mammaliochory) or diaspore handling behaviors (e.g., endozoochory, synzoochory) (see Van der Pijl, 1982). Not only are natural history studies lacking for a substantial proportion of conifer taxa, but when observational studies have been conducted there 
have often been multiple disperser groups found for a given taxon (e.g., Geldenhuys, 1992). Furthermore, specific dispersers may handle seeds in more than one way (e.g., Willson et al., 1996), and these behaviors cannot always reliably be distinguished by morphology alone (Herrera, 1989).

Overall, we recognize nine distinct functional morphotypes of conifer diaspore (Table 1; see Fig. 1 for illustrative examples). Multiple ways of achieving the same functional morphotype were recognized for six of the morphotypes, based on differences in diaspore structure (Table 1). Anemochorous morphotypes are represented by three categories: functionally single-winged, double-winged, and multiple-winged (Table 1, Fig. 1A-C). Winged diaspores were subdivided based on wing number, due to the associated differences in their inferred aerodynamic properties and resulting seed distribution potentials (Green, 1980; Matlack, 1987; Stevenson et al., 2015). Single-winged diaspores are capable of autorotating flight, where the extended wing rotates about its center of mass, generating lift and drag that slows the descent of the diaspore, thus increasing exposure time to potential winds (Augspurger, 1986; Burrows, 1986; Norberg, 1973). The dynamic stability of autorotation, even in gusty conditions, facilitates wind-borne travel over great distances (e.g., Burrows, 1986; Norberg, 1973; Stevenson et al., 2015). Double-winged diaspores roughly correspond to the "plane-winged seeds" of Burrows (1986). These are distinguished from single-winged diaspores, given that their flight characteristics appear to be less stable and their descent velocity much greater. They primarily glide in a linear, curved, or erratic manner, but may also undulate, roll about two axes, or autorotate at a less effective coning angle (Augspurger, 1986; Burrows, 1986; Stevenson et al., 2015). Multiple-winged diaspores usually have three or four wings and most likely tumble or glide (Augspurger, 1986). Some taxa with this diaspore type, however, can also produce some seeds with only two wings. 
Zoochorous diaspores also show considerable variety with four broadly defined categories: aggregate fructoid, drupe-like fructoid, baccate fructoid, and adorned fructoid (Table 1, Fig. 1D-G). Differences in their functional morphology influence the pool of potential dispersers, the handling behaviors of dispersers, and characteristics of establishment. Aggregate fructoids are characterized by having numerous small seeds per diaspore, because their ovuliferous cones consist of many fleshy fertile bract-scale complexes and are dispersed as one unit. Other fructoid morphotypes are present in taxa with reduced ovuliferous cones consisting of few fertile bract-scale complexes, and thus have usually one, but sometimes two to three (or very rarely up to nine) seeds per diaspore. Drupe-like fructoids are largest in size, globose to (ob)ovoid and often pendulous on an elongated axis, with large seeds and thick seed coats. Conversely, baccate frutoids are relatively small and spherical. Adorned fructoids are distinguished by having fleshy structures that serve to display the seed, which do not enclose the seed itself, but generally lie below, or at the base of the seed.

Plain diaspores lack wings, fleshy structures, or other obvious morphological modifications (Fig. 1I). Incidentally, this morphotype has the most variation in syndrome, including barochory, hydrochory, and zoochory (Table 1).

Nuxoid diaspores have seeds that are enclosed in hard tissues that likely serve as protection during either or both development and transport stages (Fig. 1H). Diaspores with this morphotype are primarily barochorous (Table 1).

\section{Character construction and scoring}

Diaspore composition, functional morphotype, primary dispersal syndrome, and seed coat 
modifications were scored for each taxon included in the analysis of Leslie et al. (2012) (Table S1). Data for each taxon came primarily from published literature (see Table S1 for references by taxon), and was supplemented by personal observations of living specimens at the University of California Botanical Garden at Berkeley, the San Francisco Botanical Garden, and the University of California, Berkeley campus and surrounding area. In addition to living specimens, we examined voucher specimens from the University and Jepson Herbaria at the University of California, Berkeley.

Diaspore functional morphotype, dispersal syndrome, and seed coat modifications were each treated as multistate characters (see Table 2). We coded diaspore composition in two different ways. First, we treated diaspore composition as a single multistate character with character states defined by unique combinations of structures (i.e., compound character states; Table 2). This method assumes that diaspores are functional complexes that evolve in concert. Second, we coded diaspore composition to where each additional structure that could be included in the diaspore was treated as an independent character that can be either present or absent (i.e., reductive characters, sensu Wilkinson, 1995; Table 2). Then, reconstructions for each of the five characters were compiled onto one tree to determine the composite structures of diaspores. This reductionist method of coding complex traits for ancestral state reconstructions allows for the recognition of combinations of parts that are not present in diaspores of modern taxa, under the assumption that these novel complexes would confer or maintain functionality (Wilkinson, 1995). Difference between these two methods of coding complex traits have been reviewed by Wilkinson (1995), who concluded that neither has a surplus of methodological advantages or disadvantages. Instead, justification of either coding method depends on whether the complex variation in diaspore composition is biologically independent, or if structures comprising the 
diaspore covary (Wake, 1994; Wilkinson, 1995). Therefore, we tested the phylogenetic independence of all possible character pairs using Pagel's likelihood approach for two binary characters (Pagel, 1994), as implemented in the Pagel94 analysis in the Correl Package (Midford and Maddison, 2006) in Mesquite (Maddison and Maddison, 2011). This is a modification of the methods described by Pagel (1994), in that the four parameter model is a special case of the eight parameter model. Significance of the likelihood ratio between the two models was determined by running Monte Carlo tests (1000 replicates, 10 iterations) as recommended by Midford and Maddison (2006) and Pagel (1994). We obtained significant correlations for 6 of the 10 possible character combinations (Table S2). This method, however, has been shown to provide significance when there may not be a biological basis for correlation, particularly for cases in which one of the characters only evolves once (Maddison and Fitzjohn, 2015). Wilkinson (1995) suggested that if a character complex includes some components that covary but others that do not, that it is possible that the ones that covary are also actually biologically independent. Because there is not a strong a priori justification for one coding method over the other, we present ancestral reconstructions of diaspore composition coded using both reductionist methods and compound character states.

\section{Distribution of character states and ancestral state reconstructions}

Each character was mapped onto the terminals of the time-calibrated molecular phylogeny of Leslie et al. (2012) (see Leslie et al., 2012, SI Appendix, Fig. S4 for full source tree). The phylogeny includes 489 extant species across all conifer families ( $\sim 80 \%$ of extant species diversity and 100\% generic diversity), with three cycad genera (Cycas, Zamia, and Encephalartos) as outgroups. Outgroups were scored at the generic level, and thus character 
states represent the primary condition for the genus. Using Mesquite 2.75 (Maddison and Maddison, 2011), we performed maximum parsimony and maximum likelihood ancestral state reconstructions for diaspore functional morphotype, dispersal syndrome, diaspore composition, and seed coat modifications.

The overall topology provided by Leslie et al. (2012) agrees well with other recent studies in terms of both interfamiliar relationships (e.g., Crisp and Cook, 2011; Quinn et al., 2002; Rai et al., 2008; Stefanović et al., 1998) and most suprafamilial realtionships (e.g., Escapa and Catalano, 2013; Gadek et al., 2000; Gernandt et al., 2008; Ghimire and Heo, 2014; Hao et al., 2008; Mao et al., 2012; Wang et al., 2002; Yang et al., 2012). There are, however, some minor differences among studies in the position of a few taxa within the cupressoid and callitroid clades of the Cupressaceae (see Little et al., 2004; Piggin and Bruhl, 2010), and in the position of Cephalotaxus within Taxaceae s.l. (Cheng et al., 2000; Hao et al., 2008). The alternative placements of these taxa have no major bearing on the results of our analyses. The relationships in Podocarpaceae, however, have been particularly controversial and are worth addressing further (see Knopf et al., 2012). Leslie et al.'s topology for the Podocarpaceae is mostly consistent with other analyses based only on molecular data (despite differences in taxon sampling, genes used, and optimization methods; Biffin et al., 2011; Conran et al., 2000; Sinclair et al., 2000), but there are some notable differences with topologies based on morphological or combined datasets (Hart, 1987; Kelch, 1997, 1998; Knopf et al., 2012). Due to the lack of phylogenetic concensus for the Podocarpaceae, we will briefly test how various alternative topologies for the Podocarpaceae (Kelch 1997, 1998; Knopf et al., 2012) affect the ancestral state reconstructions at deeper nodes. 
Ancestral state reconstructions were generated using Mesquite 2.75 (Maddison and Maddison, 2011). Maximum parsimony (MP) was performed as unordered, equal-weighted characters, where the cost of any state change $=1$. Parsimony optimizes ancestral states at the nodes so as to minimize the total number of character-state changes over the tree. Using this method, a single state is reconstructed for each node, and ambiguity occurs when reconstructions using alternative states result in an equal number of steps. Maximum likelihood (ML), on the other hand, provides the relative probability of alternative states for each node, using the branch lengths to model the rate of change along each branch (Pagel, 1999; Schluter et al., 1997). The ML optimization employed in Mesquite 2.75 is a one-parameter Markov k-state model, where the one parameter is the rate of change, and any change is equally probable (Lewis, 2001). ML and MP have different inherent assumptions and biases (reviewed in Cunningham, 1999; Omland, 1999), therefore using both models of evolution allows for consideration of alternative scenarios and limitations of the data. Results for the MP and ML reconstructions are shown on the same phylogeny, where likelihoods are reported as proportional likelihoods for any node where the most likely state had a value $<0.95$. Homoplasy, and the fit of the characters to the phylogeny, were measured with consistency index (CI), retention index (RI), and the rescaled consistency index (RCI). The level of homoplasy as measured by CI can be influenced by the number of character states, although this effect is reduced when there is a large amount of taxa (Cuthill et al., 2010). To evaluate whether differences in the number of character states may drive differences in CI values between the three reconstructed characters, we calculated the minimum possible $\mathrm{CI}$ for each character, $\mathrm{CI}_{\min }$, as per Cuthill et al. (2010). For diaspore composition using reductive coding, these indices were calculated both for the six individual characters and for the entire matrix. We tested for phylogenetic signal by comparing the 
character length (number of state changes) optimized on the topology to a distribution of character length optimizations for 1000 trees generated by reshuffling terminal taxa in Mesquite. The null hypothesis that the character is randomly distributed on the phylogeny was rejected if the observed character length fell outside of the upper and lower 0.05 percentile thresholds of the distribution (Maddison and Slatkin, 1991).

Comparison of the ancestral reconstructions for diaspore structural traits and functional morphotype was used to determine whether independent evolutions of a morphotype likely occurred as functional convergence or parallelism, based on having the same structural traits and following a similar trajectory of morphotype evolution. Because of the somewhat, but not fully, nested nature of dispersal syndromes and functional morphotypes, we show these two character mappings on the same tree.

\section{RESULTS}

Survey of dispersal traits in extant conifers

Over half of all genera (58\%) and species (55\%) in this analysis have diaspores that are winged (Table 3). However, they are slightly overrepresented in this study; $53 \%$ of species have winged diaspores when accounting for the total 615 recognized conifer species (Farjon, 2010). The largely zoochorous Podocarpaceae was the most underrepresented family with only 114 species in the analysis (almost all with fructoid diaspores) of the minimum estimate of 178 species in the family (Farjon, 2010). The majority of the winged diaspores are functionally single-winged (39.7\% of all species, $72 \%$ of the winged species, and $27.8 \%$ of genera, Table 3 ). 
Double-winged diaspores account for most of the remaining taxa $(13.5 \%$ of species and $26.4 \%$ of genera), as multiple-winged diaspores are comparatively rare (1.8\% of species and only four genera). Integument-derived wings are present in all three of the winged diaspore categories, whereas wings derived from the tissues of the ovuliferous scale or from the lateral edges of the bract-scale complex are restricted to the single-winged and double-winged morphotypes, respectively (Tables 1 and 3).

Zoochorous diaspores are characteristic of most of the remaining conifer taxa $(42.7 \%$ of species in this data set and $31.9 \%$ of genera). Adorned fructoids are the most abundant (18.4\% of species and $13.9 \%$ of genera), followed by baccate frutoids $(12.3 \%$ of species and $5.6 \%$ of genera), and then Drupe-like fructoids (8.0\% of species and $13.9 \%$ of genera) (Table 3). Aggregate fructoids are rare and found in only two taxa (Table 3). Plain zoochorous diaspores are found in only one genus, Pinus (19 species, 3.8\%). Particularly interesting is the variety of structures that are modified to attract dispersers. Every part of the cone has been incorporated and modified into fleshy and attractive structures (Tables 1 and 3).

Hydrochorous and barochorous diaspores are only present in a few species (four hydrochorous and seven barochorous; Table S1). Although hydrochory is almost exclusively represented by the plain morphotype, one taxon (Retrophyllum) has a morphotype typical of zoochorous diaspores (drupe-like fructoid), yet is primarily dispersed by water, although birds are also reported to consume the diaspores (Eckenwalder, 2009; Farjon, 2010). Plain diaspores also account for four of the barochorous species, with the remaining three having nuxoid diaspores (present only in Araucaria; Table 3).

Phyllocladus and Lagarostrobus (Podocarpaceae) did not fit neatly into our classification 
scheme, as they have unique compositions for their respective morphotypes. We lumped them with the most similar developmental subtype rather than create separate compositional (sub)categories to avoid obscuring broader trends with excessive detail (see Tables 1 and S1).

\section{Phylogenetic distribution of functional morphotypes and dispersal syndromes}

There is significant phylogenetic signal in the distribution of functional morphotypes and dispersal syndromes in extant conifers (i.e., states were not randomly distributed). Nonetheless, functional morphotypes and dispersal syndromes vary both across and within conifer families, with most morphotypes and syndromes having multiple independent origins (Fig. 2). Five out of the nine functional morphotypes (i.e., functionally single-winged, double-winged, baccate fructoid, drupe-like fructoid, and plain) are present in more than one family.

Ancestral character reconstructions using ML and MP were mostly congruent (Fig. 2A,D). Differences between the two optimization methods occurred only for nodes with more than one equally parsimonious state (nodes $2,7,14-16$, and 23). For most of these nodes, the ML reconstruction had strong support for a single state (Fig. 2; see Figs. S1 and S2 for species-level reconstructions of Pinus and Araucaria). The ancestral reconstruction for dispersal syndromes compared well with the functional morphotype reconstructions, with no unambiguous instances of an incompatible ancestral syndrome and morphotype (Figs. 2, S1, and S2). Ambiguous states for both morphotype and syndrome using MP (having more than one equally parsimonious reconstruction) were only found within the genera Pinus and Araucaria (Figs. S1 and S2).

There were 26 transitions in dispersal syndrome across extant conifers, 15 of which occur within the genus Pinus. Anemochory is supported by both MP and ML (>70\% proportional 
likelihood) as the plesiomorphic dispersal syndrome for all extant conifers included in this analysis (Fig. 2; see Table S2 for proportional likelihoods for dispersal syndromes). Transitions to zoochory occur in the common ancestor of the Podocarpaceae, the Taxaceae, Juniperus, and repeatedly within Pinus (Figs. 2 and S1). There are three transitions to barochory and three transitions to hydrochory (Figs. 2 and S2).

There were 42 transitions in diaspore morphotype. The ancestral functional morphology for all conifers in this analysis was ambiguous under MP, being equally parsimonious for double-winged, functionally single-winged, and drupe-like fructoid (Fig. 2A). Using ML, a double-winged morphology was most likely for both the hypothetical ancestor of all conifers and of cycads + conifers (Fig. 2D). Although the supporting proportional likelihood values were small $(<50 \%)$, they were more than double those of the next most likely states (drupe-like fructoid and functionally single-winged). Both MP and ML support a double-winged diaspore as the probable plesiomorphic state for the clade formed by all non-pinaceous conifers (Fig. 2). The state is retained in Sciadopitys, Wollemia, most of Araucaria, and half of the genera in Cupressaceae. There is at least one reversion back to double-winged in the Cupressaceae (Widdringtonia), and possibly another in Araucaria depending on whether there are one or two origins of nuxoids (Fig. S2).

Functionally single-winged diaspores occur in Pinaceae, Cupressaceae, and Agathis (Araucariaceae). This morphotype appears to have arisen seven times within extant conifer lineages (Fig. 2), not counting the likely numerous reversals within Pinus lineages in which earlier the wing was lost. It is the dominant and ancestral state for the Pinaceae, the only exceptions within the family being the multiple derived occurrences of plain seeds in Pinus 
(Figs. 2B and S1). Additionally, this morphotype is also known in some Callitris species not included in the phylogeny.

Multiple-winged diaspores are present only in the Cupressaceae, with a single origin in the Callitroid Cupressaceae (Fig. 2).

Both adorned fructoid and aggregate fructoid diaspores are exclusive to the Podocarpaceae (Fig. 2). Under MP, there are several equally parsimonious alternatives for the ancestral state of Podocarpaceae (as adorned fructoid, aggregate fructoid, or double-winged), which result in differences in the number of origins for each morphotype. Using ML, there is strong support that an adorned fructoid is the plesiomorphic condition for the family $(89 \%$ proportional likelihood), having only one origin at the base of the clade, with aggregate fructoids having two independent origins (Fig. 2A, D). Given the lack of phylogenetic concensus for Podocarpaceae, we tested the effects of different topologies on the ancestral reconstructions by manually rearranging and pruning branches to match the conflicting topologies. Using MP, the ancestral states inferred varied among the different topologies (see Fig. S3). The ancestral state for all Podocapaceae had more than one equally parsimonious solution for the Knopf et al. (2012) topology, but was reconstructed as an adorned fructoid for the Kelch et al. (1998) topology, and a drupe-like fructoid for the Kelch et al. (1997) topology. Only in the latter case were suprafamiliar nodes affected (Fig. S3).

Baccate and drupe-like fructoids occur in multiple families (Fig. 2). Drupe-like fructoids have at least four origins, three in the Podocarpaceae (except for under the Kelch et al. (1997) topology) and one in the hypothetical common ancestor of all Taxaceae (Fig. 2). Baccate fructoids have a minimum of three independent origins, representing derived states in the 
Taxaceae, Cupressaceae, and Podocarpaceae.

Plain diaspores have at least four origins in non-pinaceous taxa (Fig. 2). Within Pinaceae, the 19 occurrences of plain diaspores have several alternate reconstructions, giving between 4 and 12 independent origins by MP (each with a corresponding number of reversions to singlewinged that sums to 15 steps), or 10 by ML using the most probable state, although for a few nodes the likelihoods of plain and single-winged ancestors are very similar (Fig. S1). Nuxoid diaspores have one of the most limited distributions, occurring only within the genus Araucaria (Figs. 2 and S2). They evolved twice from double-winged ancestors, or once with a reversion to the double-winged state (Fig. S2). For both plain and nuxoid morphotypes the reconstructed transitions in dispersal syndromes coincided with transitions in morphotype (Figs. S1 and S2).

Morphotype transitions for each family are spread differently throughout their evolutionary history, reflecting contrasting evolutionary dynamics (Fig. 2). For example, transitions in Cupressaceae range from deep in the phylogeny to close to the Recent, whereas Pinaceae exhibited a long history of stasis in dispersal traits, followed by relatively recent, repeated transitions of single-winged to plain diaspores (Fig. S1). Furthermore, for the morphotypes that have arisen multiple times across conifers, the independent origins are not concentrated at specific points in time, but instead are spaced throughout conifer history.

Phylogenetic distribution of diaspore compositions and seed coat modifications

The structural composition of diaspores and the presence of seed coat modifications varies within and between extant families (Figs. 3 and 4, respectively), and both exhibita significant 
phylogenetic signal. ML and MP ancestral character state optimizations were congruent (Figs. 3 and 4). For instances of ambiguous branches under MP, the ML reconstructed state was one of the MP alternative states (Figs. 3 and 4).

For diaspore composition, the ancestral states inferred from the composite reconstruction using reductive character coding did not conflict with the ancestral states inferred using compound character states (Fig. 3A, C, D). However, between the two coding schemes, MP reconstructions differed in which nodes were ambiguous within the Araucariales (Podocarpaceae + Araucariaceae; sensu Christenhusz, 2011). The different ML reconstructions produced the same pattern of most likely ancestral states, with the exception of the ancestral diaspore composition for all Podocarpaceae (Fig. 3A, D). The reconstructions using reductive character coding did not result in any internal nodes with novel combinations of structures not seen in the living taxa. Despite the similar reconstructions of ancestral states, it is important to note that the inferred evolutionary processes and interpretation of homoplasy differ between the two coding schemes. As such, there were 37 transitions in diaspore composition under reductive coding and 28 using compound character states (Table 4).

The reconstructions of diaspore composition and seed coat modifications generated compatible ancestral states with no novel combinations of characteristics to those observed in extant taxa (Figs. 3 and 4). There were also no instances in which seed coat modifications were inferred for a node that also had additional structures incorporated into the diaspore.

In all analyses, the ancestral diaspore is reconstructed as a seed with no prominent seed coat modifications or additional structures (Figs. 3 and 4). Innovations in diaspore composition and seed coat modifications arise primarily at the family-level or at major divisions within 
families. The simplest diaspore composition-consisting only of the seed- is the only composition to occur in all extant conifer families (Fig. 3). All other diaspore compositions are restricted to a single family. Seed coat modifications occur in all families except Podocarpaceae and Pinaceae (Fig. 4). Modifications in the form of integumentary wings originate independently 2-3 times across extant conifers, and are subsequently lost in 3-4 lineages of the Cupressaceae (Fig. 4). A fleshy sarcotesta occurs in only one extant conifer lineage (Fig. 4).

Using MP, we also tested the effects of different topologies for Podocarpaceae on the ancestral reconstruction for diaspore composition (Fig. S3). The ancestral state(s) inferred for all Podocarpaceae was not consistent between topologies, and most reconstructions had more than one equally parsimonious solution (Fig. S3, C). Using reductive coding, the ancestral states for the Araucariales also had more than one optimization for each tested topology, with the diaspore possibly including both or either the ovuliferous scale and bract (Fig. S3, C). Different arrangements within Podocarpaceae did not, however, have any effect on the state(s) inferred for other suprafamilial nodes. Overall, in Podocarpaceae, the diverse combinations of components included in the diaspore appear to be generated through multiple independent gains, losses, and modifications of diaspore parts (Fig. 3), regardless of the topology used for reconstruction (Fig. S3). For the Leslie et al. topology, the diaspore composition inferred for the common ancestor of all Podocarpaceae varied depending on the coding method and optimization, resulting in several different possible reconstructions for the transitions within the family (Fig. 3). We note that the use of bract and axis in the diaspore of Podocarpaceae is more complicated than indicated simply by its inclusion in the diaspore, being employed differently in different morphotypes and subtypes (see Table 1). Therefore, the repeated independent incorporation of these structures in diaspores is probably underestimated. 
Although inferred to be the ancestral conditions for all modern conifers, diaspores that consist of simple seeds (i.e., no modifications or additional structures) only occur in a few lineages of the Cupressaceae and Podocarpaceae, and in the Pinaceae (19 spp. in Pinus, with all except one in the subgenus Strobus; Fig. S1) (Figs. 3, 4). The multiple occurrences of simple seeds nested within lineages that otherwise have winged or fleshy diaspores suggest that diaspores consisting of simple seeds in modern conifers results from loss of other structures or modifications. Within the Pinaceae this is associated with a switch to zoochory as the primary dispersal syndrome, while in Taxodium it coincides with a switch to hydrochory as the primary dispersal mechanism. For Platycladus, Microbiota, and Pherosphaera the loss of structures coincides with a switch to barochory (Figs. 2 and 3).

Functional convergence and parallelism: comparing structural traits and functional morphotypes

Comparison of the ancestral state reconstructions for diaspore functional morphotype, diaspore composition, and seed coat modifications (Figs. S4 and 4) reveals many instances of functional convergence by different structural means, but also a few instances of convergence (possible parallelism) by using the same structures or seed coat modifications via a similar pattern of morphotype character state evolution. The most prominent case of functional convergence is for the autorotating functionally single-winged diaspores, where a single wing is formed from tissue derived from the ovuliferous scale in Pinaceae, whereas in other functionally single-winged taxa wings are formed from the integument. Interestingly, of the six origins of this functional morphotype by integumentary wings, in all but one case (Callitris macleyana) the preceding node is reconstructed to have symmetric double-winged seeds (Figs. 2, 3, 4, and S4). Thus it 
appears that "single" integumentary wings may have evolved via the same functional pathway in each of these cases.

Similarly, drupe-like fructoid diaspores have arisen multiple times via different structural modifications: via fleshy sarcotestas in Cephalotaxus, fleshy arils in other Taxaceae, and fleshy epimatia/ovuliferous scales in the Podocarpaceae (Figs. 2, 3, 4, and S4). In the latter, the use of the epimatium to generate drupe-like fructoid diaspores occurs in three separate lineages, each time evolving from adorned fructoid ancestors. For two of these cases, the adorned fructoid ancestral diaspores consisted of bracts, axis, and epimatia, and the drupe-like composition resulted from loss of the bracts and axis and thus represents possible parallelisms.

Functional convergence also occurs for adorned fructoid diaspores (restricted to the Podocarpaceae). Diaspores of Lepidothamnus and the grade formed by Acmopyle, Dacrycarpus, Falcatifolium, Dacrydium, and Podocarpus have the same composition, each with attractive structures formed from bracts and the axis (receptacle), and an epimatium surrounding the seed (Figs. 2, 3, and S4). Other taxa with adorned fructoid diaspores lack a receptacle but have variously retained or gained other structures which serve to display the seed (e.g., aril, epimatium). The extent to which parallelisms may have occurred for either of these compositional methods is unclear, as there are several alternate ancestral state reconstructions for this group (Figs. 2, 3, and S3).

Within extant conifer families, plain diaspores result from the loss of different structures or modifications from the diaspore, with the exception of Lagarostrobos, which retains a dry, papery epimatium. Multiple independent origins of plain diaspores also follow different trajectories of morphotype evolution, except for those within Pinus and possibly between 
Taxodium and Platycladus + Microbiota (Figs. 2, S1, and S4). The repeated loss of the ovuliferous scale-derived wing in Pinus represents the clearest case of parallel evolution of plain diaspores.

Finally, we note that even though the phylogenetic analyses of dispersal syndrome, diaspore functional morphotype, diaspore composition, and seed coat modifications were done independently, the ancestral character state reconstructions led to compatible ecological and structural traits, except at suprafamilial nodes (Figs. 2, 3, 4, S4). These nodes are reconstructed as having winged functional morphotypes (or possibly drupe-like for nodes 1 and 2) with anemochorous dispersal syndromes (Fig. 2), but are all also reconstructed to be composed only of a seed (Fig. 3) and as lacking seed coat modifications (Fig. 4). The lack of character compatibility between structural (composition and seed coat modifications) and ecological traits (functional morphology and dispersal syndrome), in spite of internal consistency, draws into question the confidence that can be placed on the combined reconstructed states at deeper (suprafamilial) nodes. However, it is worth noting that for these nodes, functional morphotype is not unambiguously reconstructed (particularly for the common ancestor of all modern conifers), whereas seed coat modifications and diaspore composition are reconstructed with high confidence and produce the same result even with different methods of analysis. One might consider that if ecological traits are emergent properties of structural traits, then the reconstructions of diaspore composition and seed coat modifications would suggest that the ancestral state was a plain diaspore. This scenario would add four steps to the reconstruction of functional morphotype (total 45) for extant conifers and four to five steps (total 30-31) to dispersal syndrome depending on whether it was barochorous, zoochorous, or hydrochorous. In such a scenario, dispersal strategies in conifers would be even more homoplastic than could be 
detected by our reconstructions.

\section{Evolutionary dynamics of dispersal traits}

Overall, ecological traits are more homoplastic than structural traits, with faster rates of character evolution when estimated by the Mk1 model (Table 4). Note that this comparison can only consider diaspore composition using compound characters states, as the reductive coding is based on whole-matrix values rather than those for a single character, and thus are not comparable. The differences in $\mathrm{CI}_{\min }$ between characters were small (Table 4), and therefore not likely a main driver of the differences in CI. Dispersal syndromes, being roughly a broader classification of morphotypes, were the most homoplastic (Table 4) as the average number of changes per character state (6.5) was greater than that for morphotypes (4.67), seed coat modifications (2.67), and diaspore composition (3.5). Thus the rate of character evolution, as estimated by the Mk1 model, is also greatest for syndromes.

Comparing trait changes within extant conifer families (thus excluding suprafamila nodes for which there was character conflict), almost all changes in dispersal syndrome co-occur with a change in morphotype (22 of 23; Fig. 5). The exception is Retrophyllum minor, which despite having a drupe-like morphotype like the rest of its genus, is predominantly dispersed by water (although birds are known to still consume some of the fructoids). Of the 38 changes in functional morphotype within families, 20 (53\%) co-occur on the phylogeny with a change in composition, and 22 (58\%) of these also occur with a syndrome change (Fig. 5). Of these, 3 (8\%) also involve changes to the seed coat (Fig. 5). It is interesting to note that 15 of the 16 cooccurring changes in morphotype, composition, and syndrome occur within the genus Pinus. 
The descriptive part of our analysis (see Tables 1 and 3) provides a minimum estimate of convergence, recognized based on observed structural differences. In contrast, convergence recognized through ancestral state reconstructions is dependent on the topology of the phylogeny used, which is itself hypothetical in nature. Therefore, additional instances of convergence only recognized in character mapping, as well as the directionality and frequency of transitions, should also be considered hypotheses that can be supported or refuted once more information or more comprehensive phylogenies are available.

\section{DISCUSSION}

\section{Diaspores: diversity, distribution, and patterns of evolution}

\section{Convergence and divergence of diaspore morphotypes}

The nine functional morphotypes circumscribed here provide a finer-scale perspective on the diversity of dispersal strategies in conifers than previous categorizations based solely on broad dispersal vectors (syndromes) or the presence or absence of fleshiness, and reflect the combination of adaptations related to the multiple phases of dispersal. Among closely related taxa the same structures are sometimes employed in dissimilar ways (e.g., in Podocarpaceae the epimatium can be swollen and fleshy to form a drupe-like fructoid, or it can remain leathery while the axis and bracts below become fleshy to form an adorned fructoid). Conversely, among distantly related taxa, completely different structures are used to form superficially similar forms (e.g., drupe-like fructoids formed from the aril in Taxaceae or from the epimatium in Podocarpaceae). Both functional convergence and parallelism contribute substantially to the variation in dispersal strategies across conifers. In most cases parallelism characterizes the 
recurrent evolution of morphotypes within families, whereas functional convergence appears to drive the similarities between distantly related taxa. Several functional morphotypes are involved in both zoochory and anemochory, and all but one of these morphotypes have evolved multiple times. Because diaspores function in multiple phases in the entire dispersal process, selective tradeoffs between phases (e.g., transport vs. establishment; Levin et al., 1984; Manzaneda et al., 2009) may allow for a number of coexisting fitness maxima for diaspore phenotypes in the full adaptive landscape (Marshall, 2014). Thus, the morphotypes recognized here likely represent dispersal strategies that represent adaptive peaks for the combined multi-phase process of dispersal.

Factors influencing phylogenetic conservatism in diaspore functional morphology and composition

Overall there is remarkable conservatism in dispersal traits within lineages, and in particular for diaspore composition and seed coat modifications. Patterns of trait conservatism can result from multiple underlying processes that influence the range of trait expression and lability of traits. The complex interactions between ecological factors, selective tradeoffs, and genetic and developmental constraints (shaping the amplitude of inheritable variation) ultimately determine the functional morphology and composition of diaspores. As recognized by Ridley (1930), most adaptations for dispersal do not represent the generation of novel structures, but rather modification of existing structures that during earlier phases of the reproductive cycle serve other purposes. Therefore, dispersal adaptations are overlain on pre-existing parts that were (and might still be) under selection for other functions. For modern conifers, dispersal is the last major function of ovuliferous cones, where the cone can be directly incorporated into the diaspore or 
influence aspects of seed release such as drop angle and timing. The only structure with no known function other than for dispersal is the aril, which develops during the process of seed maturation. The processes throughout cone ontogeny that precede seed dispersal, specifically the role of seed cones for facilitating pollination (Leslie et al., 2015; Takaso and Owens, 1995; Tomlinson et al., 1991; Tomlinson and Takaso, 2002) and protecting the developing ovules (Leslie, 2011), are likely important factors that may impose constraints on the possible phenotypes of diaspores (see also "developmental burden" sensu Riedl, 1978). The relative importance of various cone functions is context-dependent, and thus different for taxa in contrasting environments and with different ecological and life history strategies. This in turn, may affect the paths that evolution can take. For example, in many fire-prone regions, tough serotinous cones protect seeds prior to dispersal and control the timing of seed release to correspond with a newly disturbed landscape favorable for establishment (Habrouk et al., 1999; Ne'eman et al., 2004) - it is difficult to conceive of a cone with such functions producing fleshy structures.

In addition to adaptations for specific cone functions, cone structure also influences diaspore morphology and composition through spatial limitations on ovule and wing development, the availability of different structures for incorporation into the diaspore, and underlying canalized developmental pathways. Because the structure of ovuliferous cones has a strong phylogenetic signal (e.g., Chamberlain, 1935; Eckenwalder, 1976; Escapa et al., 2012; Escapa and Catalano, 2013; Miller, 1988, 1999; Rothwell et al., 2009, 2011), its effects on diaspore phenotypes are distributed amongst lineages in a non-random way and likely contribute greatly to the conservation in both diaspore morphotypes and composition. For example, among winged-morphotypes, multiple-winged diaspores only occur in taxa with a particular 
arrangement of cone parts. Their seed cones have few bracts which are attached around the base of a central columella (e.g., Callitris rhomboidea; Farjon, 2005). When the cone is closed, the bract apices are connected above the top of the columella, and upon maturity they spread in a manner similar to a flower opening. The seeds are attached in the axil between the bract and columella, and due to their packing during development, the wings can expand in three directions. The recent single evolution of this morphotype in extant conifers may have only become possible following the evolution of this cone morphology in the Cenozoic in one group within the Cupressaceae. Among compositional types, it has been suggested that differential wing ontogeny is related to the structure of their seed cones (Farjon and Ortiz Garcia, 2003). For instance, in extant conifers, seeds with integumentary wings mostly occur in lineages for which there is no recognizable ovuliferous scale (presumably fully reduced, e.g., Cupressus, Sequoia; or fused to the cone scale, e.g., Agathis), or in which the ovuliferous scale is represented by highly reduced lobes associated with each ovule (Sciadopitys and Cunninghamia). Cones with distinct ovuliferous scales have wings formed from tissues of the cone (e.g., Pinaceae, Araucaria) rather than the integument. Overall, the similarity in cone structure within clades imposes strong limitations on the disparity in diaspore composition among closely related taxa (Fig. 3), so that divergence in dispersal strategies may be most readily accomplished by differential modification of a particular structure (e.g., differential use of the epimatium; Fig. S4). This may be the underlying reason why diaspore structural traits, especially within families, is more conserved than diaspore functional morphotypes, and why there is a tendency for recurrent evolution of functional morphotypes to be the result of parallelism within families and functional convergence between families.

Selective processes on the diaspores themselves can also lead to conservation of diaspore 
morphology, especially in the case of multi-trait selection. Compound structures that function as a single unit require that independent modifications in different structures of the compound unit result in a phenotype that can operate for the original selected process. If mutations are not coupled so that a change in one structure induces a change in the other (Klingenberg, 2008), the chance that multiple mutations occur simultaneously that can generate a still functional unit that persists in a population is likely very rare. This is especially true for a compound structure that has multiple functions (e.g., transport, protection, dormancy, germination, etc.), where tradeoffs due to conflicts of selection on the compound unit or individual structures for different functions may lead to an adaptive optimum.

A case study of functional convergence: autorotating diaspores

The homoplastic evolution of functionally single-winged, autorotating diaspores provides the most prominent example of functional convergence using different tissues of the plant, convergence using the same structures, and developmental constraints imposed by ovuliferous cone morphology.

Whereas there is only one origin for the ovuliferous scale-derived wing, the autorotating morphotype has developed from integument-derived wings at least six times in extant conifer lineages. It is also recognized in at least three other extinct conifer taxa: Manifera talaris (Looy and Stevenson, 2014) and Majonica alpina (Clement-Westerhof, 1987) of the Majonicaceae (Voltziales), and Doliostrobus taxiformis (Kvaček, 2002), the latter of which has potential affinities to Agathis (Araucariales; see Kvaček, 2002; Taylor et al., 2009). In the extant lineages, integumentary outgrowths likely progressed through a phase of lateral wings, prior to evolving the pronounced asymmetry of autorotators by the extension of one wing and the reduction of the 
other. This pattern has also been suggested for the extinct conifers Manifera talaris and Majonica alpina from the Permian (Stevenson et al., 2015). Interestingly, both Manifera and the Eocene Doliostrobus taxiformis produced a spectrum of wing morphologies, from two roughly symmetrical extended wings on the chalazal end of the seed to a single extended wing via a range of asymmetrical intermediates (Kvaček, 2002; Looy and Stevenson, 2014). This characteristic also occurs to a limited extent in modern Agathis and Fokiena (Kvaček, 2002). Overall, our reconstruction supports the idea that for autorotating lineages with integumentary wings, symmetrical lateral outgrowths were the plesiomorphic condition, and the asymmetry typifying autorotators represent convergent apomorphies (Escapa and Catalano, 2013; Looy and Stevenson, 2014; Stevenson et al., 2015.

Even in cases where a morphotype has the same structural composition in different taxa, subtle differences in developmental and morphological details also provides evidence of homoplasy. In Calocedrus, the two highly asymmetrical lateral wings fuse to form one functional wing that extends almost parallel to the seed body from the micropylar end. This developmental mode is also seen in Sylvella brevialata, seeds from the Permian that are associated with leaves of Cordaites (Meyen, 1988), a group closely related to conifers (see Taylor et al., 2009). Other influences of the cone structure on wing development may be more subtle. For example, in Austrocedrus the wing extension occurs at the micropylar end, rather than at the chalazal end as in Agathis, Manifera, and Majonica. These differences likely reflect contrasting spatial constraints on wing development due to differences in cone structure, specifically ovule orientation and placement. In Austrocedrus the ovule is in the axil of the bract and is erect (as opposed to inverted), where the wing can only extend from the micropylar end. In contrast, in Agathis the ovule is borne on the bract-scale complex and is inverted, so that the 
micropyle points toward the cone axis, and the wing extends from the chalazal end.

By spatial necessity, taxa that have seeds with an extended wing require either an open cone (i.e., Majonicaceae; Clement-Westerhof, 1987, 1988) or a cone with more elongate bractscale complexes that can accommodate a growing wing while remaining closed to protect the developing seeds. Within the Cupressaceae, taxa with the functionally single-winged morphology have ovoid cones with the bract-scale complexes growing in an upward-elongating manner (see Glyptostrobus, Calocedrus, Papuacedrus, etc.). This contrasts with the cone morphology of taxa with small double-winged seeds, which often consist of shorter, peltate bract-scale complexes (e.g., Cupressus, Sequoia, Fokienia). Agathis has broad bract-scale complexes that can accommodate a single, large-winged seed. Whether the cone morphology of some taxa enabled the development of an extended wing (as fossil Glyptostobus might indicate), or if cone-morphology reflects concurrent evolution with an elongating wing, is unclear.

\section{Ancestral states and inferences from the fossil record}

The ambiguity in, and character conflict between, the ancestral state reconstructions for the hypothetical ancestor of all extant conifers and other suprafamilial nodes calls attention to the large evolutionary gaps between extant conifer groups (Escapa et al., 2013; Escapa and Catalano, 2013; Miller, 1988; Tomlinson and Takaso, 2002). According to the time-calibrated molecular phylogeny of Leslie et al. (2012) the modern conifer families diverged between 325 and 200 million years ago. Even if the divergence times are overestimates, the morphological distance between them is considerable, which can lead to difficulties in reconstructing ancestral traits. Inclusion of stem taxa could aid in closing the large morphological gaps between extant families, thereby improving inferences of character evolution (Albert et al., 2009; Cobbett et al., 2007; 
Donoghue et al., 1989; Donoghue; 2005; Finarelli and Flynn, 2006; Miller, 1988; Novacek, 1992; Wills and Fortey, 2000; Wilson, 1992). Unfortunately, due to absence of secure phylogenies within fossil conifers and their uncertain relationships with the living taxa, we are not yet able to use the fossils directly in ancestral reconstructions. This also includes extinct coniferophyte groups thought to be sister to, or have given rise to, all modern conifers, specifically cordaitaleans and the Voltziales. Fossil conifers and their relatives do, however, have a rich fossil record, and it is informative to examine the known diaspore morphologies of late Paleozoic and early Mesozoic taxa to evaluate the possible ancestral states inferred from living taxa and assess deeper evolutionary trends in dispersal traits..

The cordaitaleans are generally regarded as the sister lineage of conifers, and are known from the late Carboniferous to the end of the Permian (Doyle and Donoghue, 1986; Hilton and Bateman, 2006; Miller, 1988; Rothwell, 1988; Rothwell et al., 2005; Taylor et al., 2009; but see also Serbet et al., 2010). Cordaitaleans primarily have plain or integumentary double-winged diaspores (Miller, 1988; Rothwell, 1988; Taylor et al., 2009), but there are also taxa with drupelike diaspores with fleshy sarcotestas (e.g., Cardiocarpus, Nucellangium; Tiffney, 1986a). Furthermore, as mentioned earlier, integument-derived functionally single-winged seeds characterize the seed form genus Sylvella Meyen, which is associated with Cordaites-like leaves (Meyen, 1988).

The Voltziales (sensu Rothwell et al., 2005; Escapa et al., 2010) consist of a large number of taxa that existed during the late Carboniferous to the late Triassic, and possibly extending into the Early Cretaceous (Herrera et al., 2015). Although their relationships to modern conifers remain obscure, they are most commonly thought to represent a paraphyletic 
group of conifers from which modern families are thought to have evolved (Axsmith and Taylor, 1997; Escapa et al., 2010; Florin, 1951; Hilton and Bateman, 2006; Miller, 1988; Rothwell et al., 2005, 2011; Serbet et al., 2010; Stewart and Rothwell, 1993; Taylor et al., 2009). These early conifers produced seeds that were either plain (e.g., Voltzia hexagona; Schweitzer, 1996) or had various seed coat modifications. Many taxa had integumentary wings that were lateral and roughly symmetrical or fully encircling the seed (e.g., Otovicia hypnoides, Telemachus spp., Timanostrobus muravievii; Escapa et al., 2010; Kerp et al., 1990; Meyen, 1997). Others have bifid apices that appear hook-like (e.g., Ferugliocladus; Archangelsky and Cúneo, 1987), or three extensions on the chalazal end of the seed (Ortiseia spp.; Clement-Westerhof, 1984), characteristics not found in extant conifers. Functionally single-winged seeds are also present in Majonica and Manifera (Clement-Westerhof, 1987; Looy and Stevenson, 2014; Stevenson et al., 2015). Two Late Permian taxa, Pseudovolzia liebeana and Ullmannia frumentaria, have been reported to have produced diaspores with fleshy sarcotestas (Schweitzer, 1963; 1986).

Among Mesozoic taxa, an interesting diaspore type not seen in extant conifers is found in the Cheirolepideaceae, a diverse family of conifers that formed a prominent component of Mesozoic floras worldwide (Alvin, 1982; Taylor et al., 2009; Watson, 1988). Some analyses suggest they fall within crown group conifers (e.g. Hilton and Bateman, 2006), where they are often allied with the Araucariaceae, Podocarpaceae, and Pinaceae (Clement-Westerhof and Van Konijnenburg-van Cittert, 1991; Escapa et al., 2013; Krassilov, 1982). They have also been suggested to be transitional between some Voltziales and modern families (Jung, 1968; ClementWesterhof and Van Konijnenburg-van Cittert, 1991; Miller, 1999). In cases where the ovuliferous cones are known, persistent bracts subtend distally lobed ovuliferous scales that each bear one or two inverted seeds. The seeds are enclosed by a "pocket-forming tissue" originating 
from the adaxial surface of the ovuliferous scale (e.g., Hirmeriella muensteri, Pararaucaria patagonica, Pararaucaria delfueyoi, and Tomaxellia biforme; Archangelsky, 1968; ClementWesterhof and Van Konijnenburg-van Cittert 1991; Escapa et al., 2012, 2013; Jung, 1968). The "pocket-forming tissue" is notably thick and parenchymatous, and it has been suggested that it may have been somewhat fleshy (Archangelsky, 1968; Clement-Westerhof and Van Konijnenburg-van Cittert, 1991; Escapa et al., 2012). The ovuliferous scales with embedded seed(s) are found dispersed, thus representing the diaspore, while the bracts are persistent on the cone axis (Archangelsky, 1968; Del Fueyo et al., 2008; Jung, 1968). Unfortunately the dispersal biology of this important group is not well understood, but they appear to have had dispersal characteristics that are not seen in modern conifers.

The range of diaspore morphologies among Mesozoic taxa that have been associated with modern families provides further insight into the complexity of dispersal evolution and the timing of appearance of morphotypes. For example, while most Mesozoic taxa associated with the Cupressaceae s.l. have integumentary double-winged diaspores (e.g. Athrotaxites berryi, Athrotaxites yumenensis, Elatides zhoui, Hughmillerites vancouverensis, and Rhombostrobus cliffwoodensis; Atkinson et al., 2014; Dong et al., 2014; Lapasha and Miller, 1981; Miller and Lapasha, 1983; Shi et al., 2014), others have plain seeds (e.g., Cunninghamites lignitum, Elatides bommeri, Elatides williamsoni, Sewardiodendron laxum, Sphenolepis kurriana; Bosma et al., 2012; Harris, 1943, 1953; Yao et al., 1998). Both morphotypes are present in genera known as early as the Jurassic. Notably, this shows that occurrences of plain diaspores in the Cupressaceae are considerably older and more prevalent than would be expected based on modern taxa only, in which it is a more recently derived state. Depending on the positioning of extinct taxa, plain diaspores may represent multiple losses of wings, or the true ancestral diaspore morphology for 
Cupressaceae in which integument-derived wings would then be a homoplastic derived trait.

The Araucariaceae attained its greatest diversity and widest distribution in the Jurassic to Early Cretaceous (Hill and Brodribb, 1999; Kunzmann, 2007; Panti et al., 2012; Taylor et al., 2009). The genus Araucaria appears first, with fossils morphologically similar to the extant sections Bunya (e.g., A. mirabilis, A. sphaerocarpa) and Eutacta (e.g., A. philipsi) present in the Jurassic (Arrondo and Petriella, 1980; Harris, 1979; Hill and Brodribb, 1999; Panti et al., 2012; Stockey 1975, 1980, 1982, 1994). These earliest representatives already possessed diaspore morphologies characteristic of their extant representatives (i.e., double-winged or nuxoid, composed of a seed plus bract and ovuliferous scale).

Fossil Pinaceae also show little variation in dispersal traits, and the earliest definitive Pinaceae with known diaspores already produced the family's characteristic ovuliferous-scalederived wings (Eathiestrobus, Upper Jurassic; Rothwell et al., 2012). There are, however, several fossil taxa that have been associated with the Pinaceae that do not show all the characteristics of crown Pinaceae (Rothwell et al., 2012). For example, Compsostrobus neotericus from the Late Triassic has two inverted seeds on each ovuliferous scale, but they are not winged (Delevoryas and Hope, 1973). Another is the Late Triassic to Early Cretaceous Schizolepidopsis, which had lax cones with ovuliferous scales that were bi- or tri-lobed and deeply dissected (Leslie et al., 2013b; Zhang et al., 2011). Some species have been described as wingless (e.g. Harris, 1979; Xu et al., 2013), however S. canicularis from the Early Cretaceous produced seeds with wings derived from the ovuliferous scale (Leslie et al., 2013b). In S. canicularis, almost the entire lobe surface of the ovuliferous scale is abscised with the seed, leaving only a simple ovoid or triangular abscission scar rather than the characteristic impression of the wing. Leslie et al. 
(2013b) suggested that the reason some fossil species have been described as not having wings may have been based on these wingless abscission scars. Allthough the phylogenetic positions of these taxa are not resolved, if they are more closely related to Pinaceae than to other living conifers, then they would support the idea that the Pinaceae may have evolved from a lineage that had plain diaspores, as suggested by the analysis of structural traits. It also raises the possibility of ovuliferous scale derived wings having arisen more than once, depending on the phylogenetic placement of Schizolepidopsis.

The fossil record of fleshy diaspores is scarce, despite the abundance of vegetative and palynological evidence for the presence of now-zoochorous families since the early Mesozoic (see Hill and Brodribb, 1999; Taylor et al., 2009). The earliest known ovulate structures assigned to Taxaceae already had the characteristic cone organization and fructoid diaspores of extant members of the family. For example, Paleotaxus from the Early Jurassic has baccate fructoids similar to extant Taxus (Florin, 1951; Stewart and Rothwell, 1993). The ovulate cones of Marskea from the Middle Jurassic consist of a terminal ovule surrounded by an aril, overall resembling the drupe-like fructoids of modern Amentotaxus and Torreya (Harris, 1976; Stewart and Rothwell, 1993; Taylor et al., 2009). Furthermore, Cretaceous seed genera Cephalotaxospermum and Vesquia consist of drupe-like structures with probable affinities to Torreya, Cephalotaxus, and Amentotaxus (Alvin, 1960; Miller, 1977; Taylor et al., 2009).

In contrast, earliest podocarpaceous fossils are notably different than the majority of their extant relatives. Most extant Podocarpaceae are characterized by having highly reduced cones consisting of only one or a few bract-scale complexes with fused components (see Methods: The structure of conifer ovuliferous cones). The earliest putative representatives of Podocarpaceae, 
however, have multiple helically arranged bract-scale complexes in a typical cone-like organization (Archangelsky and Del Fueyo, 1989). Furthermore, in most Triassic and Jurassic taxa the bracts and ovuliferous scales are free from each other, lacking the fusion of parts that typifies many of the extant taxa (e.g., Mataia, Nipaniostrobus, Nothodacrium, Rissikia, Stalagma; Miller, 1977; Roa, 1943; Townrow, 1967a, 1967b; Zhou, 1983). In some of these taxa, the tips of the ovuliferous scales are folded over so that they partially cover the seeds (e.g., Mataia, Nipaniostrobus; Miller, 1977; Roa, 1943; Townrow, 1967a), which has been interpreted by some authors to represent an early stage in the evolution of the epimatium (Archangelsky and Del Fueyo, 1989; Miller, 1977; Stewart and Rothwell, 1993). The Late Triassic Stalagma (Zhou, 1983) has a flap of tissue on the surface of the bract-scale complex that partially covers the seed, which has also been suggested as the first evidence of an epimatium (Miller, 1988; Taylor et al., 2009). It is unclear what the diaspore may have been for these fossil taxa, as well as to what extent the bracts or ovuliferous scales may have been fleshy. The Jurassic ovulate cones of Mehtaia have been described as having fleshy axes, although there are no recognizable ovuliferous scales or epimatia (Archangelsky and Del Fueyo 1989; Banjeri and Ghosh, 2006; Vishnu-Mittre, 1958). Ovulate cones with fleshy structures are more definitively known from the Cretaceous (Podocarpospermum, Trisacocladus; Archangelsky, 1966; Banerji and Ghosh, 2006; Taylor et al., 2009), some with fused parts (Bellingshausium spp.; Cantrill and Falcon-Lang, 2001). The Cretaceous Sitholeya (Vishnu-Mittre, 1958) may represent the earliest known reduced (single-seeded) cone with inverted ovule, and has been compared to living Dacrydium and Podocarpus (Archangelsky and Del Fueyo, 1989). Fossil Podocarpaceae from the Cretaceous through Cenozoic are mostly known from vegetative specimens, but reproductive structures similar to modern genera (i.e., adorned fructoids) are known from the Eocene (e.g., 
Dacrycarpus puente and Podocarpus witherdenensis; see Hill and Brodribb, 1999; Hill and Carpenter, 1991; Wilf, 2012). Overall, the fossil record for Podocarpaceae provides an important perspective on the potential ancestral dispersal characteristics for the family. First, none of the fossil representatives have winged seeds, therefore a winged morphotype is highly unlikely as the ancestral type for Podocarpaceae. From a structural perspective, the Triassic and Jurassic taxa most resemble Saxogothaea, Microcachrys, and Pherosphaera, and it may be reasonable to hypothesize that, if their cones are fleshy and dispersed as whole units, they may fall within the aggregate fructoid morphotype. Alternatively, if they are not fleshy and the seeds are dispersed alone (similar to Pherosphaera), then they may fall within the plain morphotype. Adorned fructoids remain a possible ancestral state (especially similar to Phyllocladus which has multiple fused bract-scale complexes), but only if we accept that the fossil record of less cone-like reproductive structures is far from complete and poorly understood.

Overall, the fossil record provides early evidence for many of our functional morphotypes, with only few instances of diaspore types not seen in extant taxa, demonstrating that dispersal strategies were varied and complex even during the early evolution of conifers. Examination of Mesozoic fossil taxa attributed to extant lineages suggests that diaspore characteristics are more homoplastic than can be detected by our analyses of modern conifers, particularly for functional morphotype and seed coat modifications (and by extrapolation dispersal syndrome). The presence of diverse morphologies in cordaitaleans and Voltziales generates interesting considerations for the ancestral diaspore of modern conifers. Of particular interest is that all dispersal related structures were formed only from the seed coat, consistent with our ancestral reconstruction of dispore composition (Fig. 3). While integumentary doublewinged seeds were common, it is also interesting to note that plain diaspores and drupe-like 
diaspores with fleshy sarcotestas were more prevalent in the past than would be surmised from examination of extant conifers alone. This early functional diversity for conifer diaspores unfortunately does not provide clear support for any one ancestral morhotype, but rather introduces possibilities that were not suggested by our phylogentic analysis. Furthermore, the immense diversity of extinct taxa separating modern conifer families makes confident inference of their ancestral states for homoplasious characters exceedling difficult. Miller (1988) found integumentary wings to be the plesiomorphic state in a cladistic analysis that included a cordaitalean outgroup, and inferred that integumentary wings were lost in Podocarpaceae, Taxaceae, Araucaria, and Pinaceae. Although a winged diaspore is consistent with our ancestral reconstructions of functional morphotype and dispersal syndrome, itis not supported by our analysis of seed coat modifications (Fig. 4). Conversely, if diaspore functional morphology were extrapolated from the structural trait reconstructions of suprafamilial ancestral diaspores, then our ancestral reconstructions would suggest a plain seed as the ancestral functional morphology of conifer diaspores. We consider this to also be a reasonable hypothesis, given (1) the prevalence of plain diaspores among cordaitaleans, Voltzialeans, and other Mesozoic conifers, (2) the great antiquity of lineages, and (3) the homoplasious nature of diaspore functional morphotypes and dispersal syndromes, which are shown here to be the result of convergence even more often than is recognized through ancestral reconstructions of their states directly. The story becomes more complex, however, if modern conifers have arisen from separate corditalean or voltzialean lineages, as has been suggested by several researchers (Archangelsky and Cúneo, 1987; Meyen, 1997; Miller, 1999; Serbet et al. 2010). How might this more complex view of conifer evolutionary history change our understanding of the early evolution of seed dispersal for modern conifers? 


\section{Ecological aspects of diaspore evolution}

\section{Wind-dispersed diaspores}

The repeated evolution of autorotating diaspores from other winged morphotypes suggests that increasing the seed shadow by slowing down diaspore descent results in significant fitness gains, especially when the aerodynamic mechanism confers the ability to also increase seed mass while maintaining the ability to disperse far (Green, 1993; Matlack, 1987; Stevenson et al., 2015). Beyond the typical advantages of dispersing further away from the parent plant (see Howe and Mariti, 2004; Howe and Smallwood, 1982), the increased dispersal capabilities of autorotating diaspores may also be related to specific ecological strategies that are dependent upon colonization of new sites with specific ecological requirements. For example, many autorotating taxa require direct sunlight for germination and survival throughout the seedling stage, and thus rely upon forest gap colonization or major disturbances for recruitment (e.g., Agathis australis, Libocedrus bidwillii, and Austrocedrus chilensis; Enright and Ogden, 1995). On somewhat greater timescales, improved frequency of long distance dispersal significantly improves a population's migration rate, which is important during times of rapid climate change or for taxa that occupy ephemeral habitats (Clark et al., 1998; Soons and Bullock, 2008; Stevenson et al., 2015).

Although double-winged diaspores are also capable of long distance dispersal events (e.g., Athrotaxis has been reported to travel up to 100m; Kirkpatrick et al., 2010), the frequency 
and maximum distance of these events is smaller than for autorotating diaspores. Instead, the evolutionary maintenance of double-winged diaspores may reflect a strategy which favors increased seed production at the expense of greater dispersal ability. In Cupressaceae, doublewinged diaspore taxa produce a greater number of seeds per bract-scale complex and invest less in wing tissue than single-winged taxa. Depending on the taxon, only one to two functionally single-winged diaspores are produced per bract scale complex, as compared to three to ten or more in taxa with double-winged diaspores (Farjon and Ortiz Garcia, 2002). Alternatively, it may have been sustained in many taxa because there is not sufficiently strong selection against it, or because other aspects of ovuliferous cone functions or structure limit the possible wing morphologies.

\section{Fructoid diaspores}

Biotic dispersal of seeds occurred as early as the Permian (299-252 Mya), and possibly even the Pennsylvanian (299-323 Mya) (Tiffney, 2004). The ancestral state reconstruction suggests that drupe-like, adorned, and aggregate fructoids were the first fructoids to evolve among modern conifers, and that baccate fructoids appeared later (Fig. 2). Leslie (2011) suggested that the appearance of fleshy conifer cones during the Mesozoic was the result of increased biotic interactions. The extent to which animal groups in the Mesozoic were engaged in frugivory is not well known, and for the most part potential dispersers have been inferred as being non-obligate frugivores or generalists (Tiffney, 2004). However, the original function of fleshy structures may not have been zoochory-related. It has been suggested that they first evolved as a result of the chemical defenses they provided against insect herbivory and were only later co-opted by animals as a food source (Cipollini and Levey, 1997; Herrera, 1982; Mack, 2000; Tiffney, 2004). 
Interestingly, the original function of fleshy structures may not have been related to biotic interactions at all. In Podocarpaceae, for example, the fleshy receptacle has been shown to prolong seed viability through increased desiccation resistance (Fountain et al., 1989).

Once adopted by animals as a food source, the morphology of fructoids is further driven by the interplay between the plants that produce diaspores and a temporally changing mix of animal dispersers. The intensity of selection on diaspore morphology with respect to zoochoryrelated traits can be indirectly influenced by the presence of other zoochorous species in a community through competition for available dispersers, if the relative abundances of potential dispersers and zoochorous plants are maintained over appropriate time scales. If dispersers are abundant and demand for fructoids exceeds supply, then selection intensity regarding morphology in any one particular direction is likely low due to the non-additive effects of multispecies interactions (Strauss and Irwin, 2004), which can result in an overall trend of stabilization. Conversely, if fructoid availability exceeds the demand due to limited dispersers or satiation (Hererra et at., 1994; Jordano 1994), selection may cause niche differentiation amongst zoochorous plants in a community in which diaspore morphologies are selected that specialize to a guild, or size class, of dispersers (Herrera 1985; Jordano, 1995; Lord, 2004). Of course, zoochory-related selection occurs against a backdrop of selection on the full spectrum of traits related to non-transport phases of dispersal (Herrera et al., 1994), which has consequences for the phenotype of fructoid diaspores that should not be underestimated. For example, Ericksson (2000) concluded that for angiosperms in the late Mesozoic to early Cenozoic, the increase in diversity of seed and fruit size was most likely associated with selection for enhanced establishment in low light conditions, rather than driven primarily by animal dispersal. Overall, we think that multiple selective processes are acting in concert, driving phenotypes toward a 
number of local optima in the adaptive landscape.

Our results suggest that following their initial appearance in modern lineages in the Mesozoic (see Ancestral states and inferences from the fossil record), the fructoid morphologies have not only persisted to the present day, but have repeatedly evolved through time (Fig. 2), despite major differences in the faunal communities present. A similar trend has also been recognized for angiosperms throughout the Cenozoic (Eriksson, 2000; Bolmgren and Eriksson, 2005; Bremer and Eriksson, 1992). These observations are consistent with fruit-disperser mutualisms being the result of "diffuse" evolution rather than species-specific coevolution (e.g., Herrera, 1983; Howe 1984, 1986; Howe and Smallwood, 1982; Jordano, 1993; Tiffney, 1986a, 2004). As such, zoochorous diaspore morphologies are influenced by many simultaneously acting, yet non-aligned selective forces, exerted by a complex network of various mutualisms that change through space and time, resulting in a lack of strong and clear disperser-induced evolutionary directionality (Jordano, 1993; 1994; Nogales et al., 2013). Ecological redundancy in the network of dispersers, coupled with morphologies moving towards adaptive peaks due to continual selection in a multi-phase process, can lead to stabilization of fructoid morphology even against a backdrop of faunal changes and turnover.

\section{Plain diaspores}

Plain diaspores are associated with three out of four of our dispersal syndromes, which in modern conifers appear to be context-dependent and related to the habitat and ecological strategy of the plant. For example, Taxodium grows in riparian and other wet habitats and its diaspores are wingless, buoyant, and dispersed by water. Microbiota is a low-growing shrub that forms monodominant populations on stony slopes, mainly above the treeline (Artyukova et al., 2009). 
The plain seeds drop and germinate close to the parent plant following fire (Artyukova et al., 2009).

An important dispersal mechanism among conifer lineages with plain diaspores is cache burial by birds and small mammals, which has been particularly well studied in pines (see Tomback and Linhart, 1990; Vander Wall et al., 2005). In Pinus, twenty (nineteen in this study) taxa have relatively large wingless seeds, and the evolutionary history of the transition from winged to wingless seeds in pines is directly associated with a specific group of dispersers: jays and nutcrackers (see Tomback and Linhart, 1990; Vander Wall and Balda, 1977). For these zoochorous plain diaspores, the seeds are notably larger than their non-zoochorous relatives, which coincides with changes in seed cone morphology and mechanisms of seed release (Tomback and Linhart, 1990). This may represent one of the few clear cases of bidirectional species-complex co-evolution in conifer dispersal strategies (see Vander Wall and Balda, 1977). The transition has occurred independently many times in Pinus (between four and twelve times suggested by MP, and ten times by ML), which illustrates that reversals (i.e. loss of structures and regaining them or vice versa) in this instance were not uncommon (Fig. S1). Otherwise, the family has been characterized by remarkable niche conservatism in dispersal traits through time, lasting well over 200 million years. The repeated evolution of the plain diaspores in Pinus comprises a large proportion of the overall combined changes in dispersal traits (15 changes, including reversals, for each trait except seed coat modifications; Figs. S1, 5), and based on the time-calibrated phylogeny we used (Leslie et al. 2012; Fig. S1), most of these have occurred largely within the last ten million years. This suggests that in the rare cases of co-evolution, the directionality of selection is simple and persistent enough it can influence morphology across many closely-related species on relatively short evolutionary time scales. 
We note that although seed size was not explored in this study, it can provide a way to evaluate dispersal syndromes of plain diaspores when the vector can not be observed, such as in the fossil record. In this regard, it is worth mentioning that of the plain diaspores known from Mesozoic conifers are generally small in size, more similar to anemochorous integumentarywinged seeds of modern conifers than those of modern zoochorous ones in Pinus.

\section{Macroevolutionary patterns}

Analysis of the directionality and frequency of morphotype transitions and their relation with different dispersal vectors within extant conifer families suggests several trends in dispersal evolution for conifers (Fig. 6). Most striking is that morphotype transitions between winged diaspores and fructoids were infrequent and unidirectional, occurring only as transitions from anemochory to zoochory (Fig. 6). With the exception of the repeated loss of wings and switch to zoochory in Pinus, transitions were more frequent within these two syndromes than between them. Differences in selection regimens may be responsible for the higher propensity to change dispersal strategies but use the same vector rather than to change vectors entirely. For anemochorous taxa, the main natural selection agents are environmentally or physiologically based, whereas for zoochorous taxa selection is shaped by (the community of) dispersers. The latter imposes a more active selection regime, which suggests zoochorous species may end up "stuck" in this syndrome. Furthermore, structural adaptations for zoo- and anemochory are highly specialized, and the developmental and genetic changes required to go from one to the other are likely extensive, posing a formidable barrier for innovation. Interestingly, transitions to barochorous or hydrochorous strategies occur from both anemochorous and zoochorous morphologies (Fig. 6), and are most associated with the loss of structures. For hydrochorous and 
barochorous plain diaspores, there are no transitions back to other syndromes, which would require either new modifications or the reincorporation of lost structures back into the diaspore. This appears to be different for the zoochorous plain diaspores in Pinus, of which there are several inferred transitions back to functionally single-winged diaspores. Although evolutionary loss would seem the easiest structural change, such transitions only account for approximately one third of all morphotype transitions, suggesting that natural selection favoring more complex diaspores is relatively pervasive across conifers. The overall pattern that emerges from the ancestral reconstructions and examination of the fossil record, is that ecological radiation from a diaspore that most likely consisted only of a seed resulted in a variety of adaptive strategies for dispersal by all vectors, through the modification and incorporation of a diversity of structures into the diaspore (Fig. 6). There was an overall tendency, albeit infrequent, for the "escape" from the anemochorous syndrome, as transitions back to anemochory were rare, and completely absent in the case of fructoids. Following transitions to zoochory or anemochory, lineages diversified in their strategies within their respective syndromes. Overall, however, transitions between dispersal strategies are infrequent compared to branching events with an absence of any dispersal changes. Conservatism in diaspore morphology seems to be the general rule amongst conifer lineages.

\section{Limitations of study}

Categorical classification of natural phenomena always has limitations. In this study, for example, the morphotype categorization neglects some important traits known to affect aspects of dispersal strategies, such as color and seed sizes (Leishman et al., 2000; Willson and Whelan, 1990). Further, the delineation of wind-dispersal strategies based upon theoretical and observed 
differences in aerodynamic properties deserves more attention, particularly through experimental studies which can help evaluate whether different inferred dispersal potentials of winged diaspores actually translates into different dispersal capabilities in real world conditions. For example, the unusually heavy and well-protected double-winged diaspores of most Araucaria species may warrant separation into their own category.

Similarly, diaspore composition provides only a rough proxy for different developmental attributes that lead to similar functional morphologies. For all taxa included within a morphotype subcategory (Table 1), the composition is in many cases the result of homoplasy, but may also represent true homology (i.e., inherited from a common ancestor). They may also be the result of developmental attributes which, if described in more detail, would indicate convergence. This is probably the case for the receptacle of adorned fructoids within the Podocarpaceae (Leslie, 2011). Furthermore, using the same structures to compose the diaspore does not necessarily translate into developmental equivalence, so the presence or degree of inferred parallelism at a finer diaspore classification level remains uncertain. Structures may be employed in different ways, as exemplified by the various uses of the bracts and axis in Podocarpaceae and Juniperus. Nor do we know at this time whether similar use of the same structures is achieved by the same genetic pathway. Diaspore compositions are useful, however, for recognizing how structures are altered to confer different functionalities. The most obvious cases in this study comprise morphotype transitions unrelated to changes in composition (Fig. 5).

The distribution among extant taxa, and inferred ancestral states for diaspore morphotype and composition are dependent on the topology of the phylogenetic tree used. As stated previously, the phylogeny used here is the most comprehensive available to date, but it does not 
include extinct taxa. Tracing the history of dispersal traits on a phylogeny that includes fossil taxa may alter the interpretation of transitions, especially at the deeper nodes.

\section{Open questions}

One of the goals of this paper is to stimulate further work towards an integrative understanding of the ecology and evolution of seed dispersal and the dynamic nature of ovuliferous cone evolution in conifers. Recognition of a homoplastic phenotypic evolution is only a first step towards understanding why, out of all morphological possibilities, only certain morphologies or syndromes have repeatedly evolved (Wake et al., 2011). The next steps in understanding this process include evaluating how different morphotypes are related to traits involved in seed germination and seedling establishment, how they translate into realized effects on both local and long-distance dispersal (Ronce and Clobert, 2012), and what the overall effect is on the realized distributions of taxa. The recognition of functionally convergent morphotypes provides an opportunity to study: (1) costs associated with the pre-departure phase of dispersal using similar phenotypes that follow different developmental pathways (see Bonte et al., 2012; Rubio de Casas et al., 2012); and, (2) how the multifunctionality of ovuliferous cones, such as pollination and protection, relates to diaspore morphology and limitations on dispersal modes. Useful areas of focus include the exploration of diaspore structure through developmental and genetic studies (particularly for evaluating potential parallelisms), and empirical studies on the relationships between dispersal vectors and fructoid phenotypes. Of key importance to understanding the evolution of dispersal in conifers is to directly incorporate fossils in the reconstruction of their phylogeny. Because seed dispersal is the primary means by which plants move across the spatially and temporally heterogeneous landscape, we consider such investigations central to 
gaining a better understanding of the ability of plants to cope with changing environments.

\section{Conclusions}

Dispersal strategies are more diverse than commonly assumed for conifers, demonstrated by the nine diaspore functional morphotypes described herein. Most morphotypes have evolved several times, either within clades by using identical structures in similar ways (parallelism), or in more distantly related taxa by altering different structures to form the same gross phenotype (functional convergence). Functionally single-winged diaspores and drupe-like fructoids in particular, have evolved multiple times by functional convergence and possible parallelism. Morphotypes that have evolved repeatedly, especially among distantly related taxa, likely represent adaptive peaks, i.e. optimal phenotypes that reflect selective tradeoffs for the multiple phases of dispersal.

Dispersal syndromes, diaspore functional morphotypes, diaspore compositions, and seed coat modifications all exhibit a strong phylogenetic signal. This may reflect genetic and developmental constraints and the influences of the sequential multiplicity of cone functions before and during the multiple phases of dispersal. Structural traits are more conserved when compared to functional morphotypes or syndromes. This may reflect the strong limits that highly conserved cone structures impose on the disparity in diaspore composition and the presence of seed coat modifications. As a result, divergence in dispersal strategies among closely related taxa may be most readily accomplished by differential modification of a particular structure. The conservatism in morphotypes indicates that selection to maintain traits within lineages may be strong, or that disruptive selection that may cause the divergence of traits is not strong enough to overcome the adaptive minima between phenotypic optima. 
Each of the fructoid morphotypes has evolved independently multiple times and likely at different times throughout history. The stability of fructoid morphotypes over evolutionary timescales, despite changing fauna and community compositions, supports the idea of diffuse relationships with many dispersers simultaneously, and likely ecological redundancy of different dispersers through time. Our study suggests that a seed lacking additional structures was the ancestral condition of modern conifers, although the ecological aspects of such a diaspore remain uncertain. Further investigations of fossil conifers and their relation to modern families will be helpful to better understand the early evolutionary dynamics of conifer dispersal.

Within modern conifer families, transitions between winged to fructoid morphotypes have been relatively infrequent and only occurred as a shift from wind to animal dispersal. Changes in dispersal strategies occurred more frequently among fructoid and winged types than between them. This may reflect inherent difficulties of more drastic structural modifications and change in selective forces necessary to drive transitions from wind to animal dispersal, and particularly the reverse. In contrast, the transition to dispersal by gravity or water, appears to be possible from either wind or animal dispersed types, and mostly driven by the life history strategy of the organism. Conifers provide a dynamic system for the study of dispersal, from aspects of developmental constraints, to drivers of morphological adjustments as they relate to ecological strategies, and to broad-scale evolutionary patterns. Considered in the context of evolutionary time, this can be informative about the selective pressures that shaped past ecosystems, and the biogeographical history of conifers. We hope that this paper provides a first step in synthesizing some of the morphological, evolutionary, and ecological ideas that will facilitate future research in conifer evolutionary-ecological dynamics. 


\section{ACKNOWLEDGMENTS}

We gratefully thank Andrew Leslie for generously providing his and his colleagues' phylogeny. We also thank Jim Doyle, Nathalie Nagalingum, Robert Stevenson, and Greg Jordan for advice and helpful discussions, and David Ackerly for reviewing an earlier draft of this manuscript. Ignacio Escapa and an anonymous reviewer provided thoughtful and critical reviews, all of which greatly improved the manuscript. We acknowledge the University of California and Jepson Herbaria for access to their conifer cone collection. This material is based upon work supported by the National Science Foundation Graduate Research Fellowship under Grant No. DGE 1106400 to Dori Contreras. Any opinions, findings, and conclusions or recommendations expressed in this material are those of the authors and do not necessarily reflect the views of the National Science Foundation. This research was supported by the Hellman Fellowship and the University of California Museum of Paleontology. This is University of California Museum of Paleontology Contribution No. 2066.

\section{WORKS CITED}

Ackwood, M.O., Jurado, E., Leishman, M., Westoby, M., 1993. Geographic ranges of plant species in relation to dispersal morphology, growth form, and diaspore weight. J. Biogeogr. 20, 563-571. http://dx.doi.org/10.2307/2845727

Albert, J.S., Johnson, D.M. Knouft, J.H., 2009. Fossils provide better estimates of ancestral body size than do extant taxa in fishes. Acta Zool.-Stockholm 90 (Suppl. 1), 357-384. http://dx.doi.org/10.1111/j.1463-6395.2008.00364.x 
Alcántara, J.M., Rey, P.J., 2003. Conflicting selection pressures on seed size: evolutionary ecology of fruit size in a bird-dispersed tree, Olea europaea. J. Evol. Biol. 16, 11681176. http://dx.doi.org/10.1046/j.1420-9101.2003.00618.x

Alvin, K.L., 1960. On the seed Vesquia tournaisii C.E. Bertrand, from the Belgian Wealden. Ann. Bot. 24, 508-515.

Alvin, K.L., 1982. Cheirolepidiaceae: biology, structure, and paleoecology. Rev. Palaeobot. Palynol. 37, 71-98.

Archangelsky, S., 1966. New gymnosperms from the Ticó flora, Santa Cruz Province, Argentina. Bull. Br. Mus. (Nat. Hist.) Geol. 13, 262-295.

Archangelsky, S., 1968. On the genus Tomaxellia (Coniferae) from the Lower Cretaceous of Patagonia (Argentina) and its male and female cones. J. Linn. Soc. (Bot.) 61, 153-165. Archangelsky, S., Cúneo, R., 1987. Ferugliocladaceae, a new conifer family from the Permian of Gondwana. Rev. Palaeobot. Palynol. 51, 3-30.

Archangelsky, S., Del Fueyo, G., 1989. Squamastrobus gen. n., A Fertile Podocarp from the Early Cretaceous of Patagonia, Argentina. Rev. Palaeobot. Palynol. 59, 109-126.

Arrondo, O.G., Petriella, B., 1980. Alicurá, nueva localidad plantífera liásica de la provincia de Neuquén, Argentina. Ameghiniana 17, 200-215. Artyukova, E.V., Kozyrenko, M.M., Gorovoy, P.G., Zhuravlev, Y.N., 2009. Plastid DNA variation in highly fragmented populations of Microbiota decussata Kom. (Cupressaceae), an endemic to Sikhote Alin Mountains. Genetica 137, 201-212. http://dx.doi.org/10.1007/s10709-009-9386-7

Atkinson, B.A., Rothwell, G.W., Stockey, R.A., 2014. Hughmillerites vancouverensis sp. nov. and the Cretaceous diversification of Cupressaceae. Am. J. Bot. 101, 1-12. http://dx.doi.org/10.3732/ajb.1400369 
Augspurger, C.K., 1986. Morphology and dispersal potential of wind-dispersed diaspores of neotropical trees. Am. J. Bot. 73, 353-363.

Axsmith, B.J., Taylor, T.N., 1997. The Triassic conifer seed cone Glyptolepis. Rev. Palaeobot. Palynol. 96, 71-79.

Bacles, C.F.E., Lowe, A.J., Ennos, R.A., 2006. Effective seed dispersal across a fragmented landscape. Science 311, 628. http://dx.doi.org/10.1126/science.1121543

Banerji, J., Ghosh, A.K., 2006. Podospermum gen. et sp. nov., an Acmopyle-like dispersed silicified ovule/seed from Lower Cretaceous intertrappean beds of the Rajmahal Basin, India. Cret. Res. 27, 707-711. http://dx.doi.org/10.1016/j.cretres.2006.03.003

Benkman, C.W., 1995. Wind dispersal capacity of pine seeds and the evolution of different seed dispersal modes in pines. Oikos 73, 221-224. http://dx.doi.org/10.2307/3545911

Bessey, C.E., 1902. The morphology of the pine cone. Bot. Gazette 33, 157-159.

Biffin, E., Conran, J. G., Lowe, A. J., 2011. Podocarp evolution: a molecular phylogenetic perspective, in: Turner, B.L., Cernusak L.A. (Eds.), Ecology of Podocarpaceae in Tropical Forests. Smithsonian Smithsonian Institution Scholarly Press, Washington, D.C., USA, pp 1-20.

Bonte, D., Van Dyck, H., Bullock, J.M., Coulon, A., Delgado, M., Gibbs, M., Lehouck, V., Matthysen, E., Mustin, K., Saastamoinen, M., Schtickzelle, N., Stevens, V.M., Vandewoestijne, S., Baguette, M., Barton, K., Benton, T.G., Chaput-Bardy, A., Clobert, J., Dytham, C., Hovestadt, T., Meier, C.M., Palmer, S.C.F., Turlure, C., Travis, J.M.J., 2012. Costs of dispersal. Biol. Rev. 87, 290-312. http://dx.doi.org/10.1111/j.1469185x.2011.00201.x

Bosma, H.F., Kunzmann, L., Kvaček, J., van Konijnenburg-van Cittert, J.H.A., 2012. Revision 
of the genus Cunninghamites (fossil conifers), with special reference to nomenclature, taxonomy and geological age. Rev. Palaeobot. Palynol. 182, 20-31. http://dx.doi.org/10.1016/j.revpalbo.2012.06.004

Bolmgren, K., Eriksson, O., 2005. Fleshy fruits - origins, niche shifts, and diversification. Oikos $109,255-272$.

Bremer, B., Eriksson, O., 1992. Evolution of fruit characters in the tropical family Rubiaceae. Biol. J. Linn. Soc. 47, 79-95. http://dx.doi.org/10.1111/j.1095-8312.1992.tb00657.x

Burlingame, L.L., 1915. The morphology of Araucaria brazilensis. II. The ovulate cone and female gametophyte. Bot. Gaz. 57, 490-508.

Burrows, F.M., 1986. The aerial motion of seeds, fruits, spores and pollen, in: Murray, D.R. (Ed.), Seed Dispersal. Academic Press, Sydney, New South Wales, pp. 2-46.

Cantrill, D.J., Falcon-Lang, H.J., 2001. Cretaceous (Late Albian) coniferales of Alexander Island, Antarctica. 2. Leaves, reproductive structures and roots. Rev. Palaeobot. Palynol. 115, 119-145. http://dx.doi.org/10.1016/S0034-6667(01)00053-7

Carlsbecker, A., Sundström, J.F., Englund, M., Uddenberg, D., Izquierdo, L., Kvarnheden, A., Vergara-Silva, F., Engström, P., 2013. Molecular control of normal and acrocona mutant seed cone development in Norway spruce (Picea abies) and the evolution of conifer ovule-bearing organs. New Phytol. 200, 261-275. http://dx.doi.org/10.1111/nph.12360

Chamberlain, C.J., 1935. Gymnosperms, structure and evolution. AC Black, London, UK.

Chapin, F.S. III, Autmn, K., Pugnaire, F., 1993. Evolution of suites of traits in response to environmental Stress. Amer. Nat. 142, S78-S92.

Cheng, Y., Nicolson, R.G., Tripp, K., Chaw, S-M., 2000. Phylogeny of Taxaceae and Cephalotaxaceae genera inferred from chloroplast matk gene and nuclear rDNA ITS 
region. Mol. Phylogenet. Evol. 14, 353-365. http://dx.doi.org/10.1006/mpev.1999.0710

Christenhusz, M.J.M., Reveal, J.L., Farjon, A., Gardner, M.F., Mill, R.R., Chase, M.W., 2011. A new classification and linear sequence of extant gymnosperms. Phytotaxa 19, 55-70.

Cipollini, M.L., Levey, D.J., 1997. Why are some fruits toxic? Glycoalkaloids in Solanum and fruit choice by vertebrates. Ecology 78, 782-798.

Clark, J.S., Fastie, C., Hurtt, G., Jackson, S.T., Johnson, C., King, G.A., Lewis, M., Lynch, J., Pacala, S., Prentice, C., Schupp, E.W., Webb III, T., Wyckoff, P., 1998. Reid's Paradox of rapid plant migration. BioScience 48, 13-24. http://dx.doi.org/10.2307/1313224

Clement-Westerhof, J.A. 1984. Aspects of Permian palaeobotany and palynology. IV. The conifer Ortiseia Florin from the Val Gardena formation of the Dolomites and the Vicentinian Alps (Italy) with special reference to a revised concept of the Walchiaceae (Goppert) Schimper. Rev. Palaeobot. Palynol. 41, 51-166.

Clement-Westerhof, J.A., 1987. Aspects of Permian palaeobotany and palynology, VII. The Majonicaceae, a new family of Late Permian conifers. Rev. Palaeobot. Palynol. 52, 375402.

Clement-Westerhof, J.A., 1988. Morphology and phylogeny of Paleozoic conifers, in: Beck, C.B. (Ed.), Origin and Evolution of Gymnosperms. Columbia Univ. Press, New York, pp. 298337.

Clement-Westerhof, J.A., van Konijnenburg-van Cittert, J.H.A., 1991. Hirmeriella muensteri: New data on the fertile organs leading to a revised concept of the Cheirolepidiaceae. Rev. Palaeobot. Palynol. 68, 147-179. http://dx.doi.org/10.1016/0034-6667(91)90062-8 
Cobbett, A., Wilkinson, M., Wills, M.A., 2007. Fossils impact as hard as living taxa in parsimony analyses of morphology. Syst. Biol. 56, 753-766. http://dx.doi.org/10.1080/10635150701627296

Conran, J.G., Wood, G.M., Martin, P.G., Dowd, J.M., Quinn C.J., Gadek, P.A., Price, R.A., 2000. Generic relationships within and between the gymnosperm families Podocarpaceae and Phyllocladaceae based on an analysis of the chloroplast gene rbcL. Aust. J. Bot. 48, 715-724. http://dx.doi.org/10.1071/BT99062

Crisp M.D., Cook, L.G., 2011. Cenozoic extinctions account for the low diversity of extant gymnosperms compared with angiosperms. New Phytol. 192, 997-1009. http://dx.doi.org/10.1111/j.1469-8137.2011.03862.x

Cunningham, C.W., 1999. Some limitations of ancestral character-state reconstruction when testing evolutionary hypotheses. Syst. Biol. 48, 665-674.

Cuthill, J.F.H., Braddy, S.J., Donoghue, P.C.J., 2010. A formula for maximum possible steps in multistate characters: isolating matrix parameter effects on measures of evolutionary convergence. Cladistics 26, 98-102. http://dx.doi.org/10.1111/j.1096-0031.2009.00270.x

Davis, M.B., Shaw, R.G., 2001. Range shifts and adaptive responses to Quaternary climate change. Science 292, 673-679. http://dx.doi.org/10.1126/science.292.5517.673

Delevoryas, T., Hope, R.C., 1973. Fertile coniferophyte remains from the Late Triassic Deep River Basin, North Carolina. Am. J. Bot. 60, 810-818.

Del Fueyo, G.M., Archangelsky, S., Lloren, M., Cúneo, R., 2008. Coniferous ovulate cones from the lower Cretaceous of Santa Cruz Province, Argentina. Int. J. Plant Sci. 169, 799-813. http://dx.doi.org/10.1086/533608

Dong, C., Sun, B-N, Wu, J-Y, Du, B-X, Xu, X-H, Jin, P-H., 2014. Structure and affinities of 
Athrotaxites yumenensis sp. nov. (Cupressaceae) from the Lower Cretaceous of northwestern China. Cret. Res. 47, 25-38. http://dx.doi.org/10.1016/j.cretres.2013.09.012

Donoghue, M.J., 1989. Phylogenies and the analysis of evolutionary sequences, with examples from seed plants. Evolution 43, 1137-1156. http://dx.doi.org/10.2307/2409353

Donoghue, M.J., Doyle, J.A., Gauthier, J., Kluge, A.G., Rowe, T., 1989. The importance of fossils in phylogeny reconstruction. Annu. Rev. Ecol. Syst. 20, 431-460.

Donoghue, P.C.J., 2005. Saving the stem group: a contradiction in terms? Paleobiology 31, 553558.

Doyle, J.A., Donoghue, M.J., 1986a. Relationships of angiosperms and Gnetales: a numerical cladistic analysis, in: Thomas, B.A., Spicer, R.A. (Eds.), Systematic and Taxonomic Approaches in Paleobotany. Oxford Univ. Press, London, pp. 177-198.

Doyle, J.A., Donoghue, M.J., 1986b. Seed plant phylogeny and the origin of angiosperms: an experimental cladistics approach. Bot. Rev. 52, 321-431.

Dynesius, M., Jansson, R., 2000. Evolutionary consequences of changes in species' geographical distributions driven by Milankovitch climate oscillations. Proc. Natl. Acad. Sci. U.S.A. 97, 9115-9120. http://dx.doi.org/10.1073/pnas.97.16.9115

Eckenwalder, J.E., 1976. Re-evaluation of Cupressaceae and Taxodiaceae: a proposed merger. Madrono 23, 237-256.

Eckenwalder, J.E., 2009. Conifers of the World. Timber, Portland.

Edwards, W., Westoby, M., 1996. Reserve mass and dispersal investment in relation to geographic range of plant species: phylogenetically independent contrasts. J. Biogeogr. 23, 329-338. http://dx.doi.org/10.1046/j.1365-2699.1996.00034.x

Englund, M., Carlsbecker, A., Engström, P., Vergara-Silva, F., 2011. Morphological “primary 
homology" and expression of AG-subfamily MADS-box genes in pines, podocarps, and yews. Evol. Dev. 13, 171-181. http://dx.doi.org/10.1111/j.1525-142X.2011.00467.x

Enright, N.J, Ogden, J., 1995. The southern conifers - a synthesis, in: Enright, N.J., Hill, R.S. (Eds.), Ecology of the Southern Conifers. Melborne University Press, Melborne, pp. 271287.

Eriksson, O., Friii, E.M., Löfgren, P., 2000. Seed size, fruit size, and dispersal systems in angiosperms from the Early Cretaceous to the Late Tertiary. Am. Nat. 156, 47-58.

Escapa, I.H., Catalano, S.A., 2013. Phylogenetic analysis of Araucariaceae: integrating molecules, morphology, and fossils. Int. J. Plant Sci. 174, 1153-1170. http://dx.doi.org/10.1086/672.369

Escapa, I., Cúneo, R., Axsmith, B., 2008. A new genus of Cupressaceae (senu lato) from the Jurassic of Patagonia: implications for conifer megasporangiate homologies. Rev. Palaeobot. Palynol. 151, 110-122. http://dx.doi.org/10.1016/j.revpalbo.2008.03.002

Escapa, I.H., Cúneo, N.R., Rothwell, G., Stockey, R.A., 2013. Pararaucaria delfueyoi sp. nov. from the Late Jurassic Canadon Calcareo Formation, Chubut, Argentina: insights into the evolution of the Cheirolepidiaceae. Int. J. Plant Sci. 174, 458-470. http://dx.doi.org/10.1086/668612

Escapa, I.H., Decombeix, A.-L., Taylor, E.L., Taylor, T.N., 2010. Evolution and relationships of the conifer seed cone Telemachus: evidence from the Triassic of Antarctica. Int. J. Plant. Sci. 171, 560-573. http://dx.doi.org/10.1086/651948

Escapa, I.H., Rothwell, G.W., Stockey, R.A., Cúneo, N.R., 2012. Seed cone anatomy of Cheirolepidiaceae (Coniferales): reinterpreting Pararaucaria patagonica Weiland. Am. J. Bot. 99, 1058-1068. http://dx.doi.org/10.3732/ajb.1100544 
Farjon, A., 2005. A Monograph of Cupressaceae and Sciadopitys. Royal Botanic Gardens, Kew, UK.

Farjon, A., 2010. A handbook of the World's conifers. Brill Academic Publishers, Leiden, the Netherlands.

Farjon, A., Ortiz Garcia, S., 2002. Towards the minimal conifer cone: ontogeny and trends in Cupressus, Juniperus and Microbiota (Cupressaceae s. str.). Bot. Jahrb. Syst. 124, 129147. http://dx.doi.org/10.1127/0006-8152/2002/0124-0129

Farjon, A., Ortiz Garcia, S., 2003. Cone and ovule development in Cunninghamia and Taiwania (Cupressaceae sensu lato) and its significance for conifer evolution. Am. J. Bot. 90, 8-16. http://dx.doi.org/10.3732/ajb.90.1.8

Finarelli, J.A., Flynn, J.J., 2006. Ancestral state reconstruction of body size in the Caniformia (Carnivora, Mammalia): the effects of incorporating data from the fossil record. Syst. Biol. 55, 301-313. http://dx.doi.org/10.1080/10635150500541698

Florin, R., 1938-1945. Die Koniferen des Oberkarbons und des unteren Perms. I-VIII. Palaeontogr. Abt. B 85, 1-729.

Florin, R., 1951. Evolution of cordaites and conifers. Acta. Hortic. Berg. 15, 285-388.

Florin, R., 1954. The female reproductive organs of conifers and taxads. Biol. Rev. 29, 367-389. http://dx.doi.org/10.1111/j.1469-185X.1954.tb01515.x

Fountain, D.W., Holdsworth, J.M., Outred, H.A., 1989. The dispersal unit of Dacrycarpus dacrydioides (A. Rich.) de Laubenfels (Podocarpaceae) and the significance of the fleshy receptacle. Bot. J. Linn. Soc. 99, 197-207. http://dx.doi.org/10.1111/j.10958339.1989.tb00399.x. 
Gadek, P.A.., Alpers, D.L., Heslewood, M.M., Quinn, C.J., 2000. Relationships within Cupressaceae sensu lato: a combined morphological and molecular approach. Am. J. Bot. 87, 1044-1057.

Geldenhuys, C.J., 1992. Reproductive biology and population structures of Podocarpus falcatus and P. latifolius in southern Cape forests. Bot. J. Linn. Soc. 112, 59-74. http://dx.doi.org/10.1006/boj1.1993.1041

Gernandt, D.S., Magallón, S., López, G.G., Flores, O.Z., Willyard, A., Liston, A., 2008. Use of simultaneous analysis to guide fossil-based calibrations of Pinaceae phylogeny. Int. J. Plant Sci. 169, 1086-1099. http://dx.doi.org/10.1086/590472

Ghimire, B., Heo, K., 2014. Cladistic analysis of Taxaceae s.l. Plant Syst. Evol. 300, 217-223. http://dx.doi.org/10.1007/s00606-013-0874-y

Gifford, E.M., Foster, A.S., 1989. Morphology and Evolution of Vascular Plants (3 ${ }^{\text {rd }}$ ed.). Freeman, New York.

Givnish, T.J., 1980. Ecological constraints on the evolution of breeding systems in seed plants: dioecy and dispersal in gymnosperms. Evolution 34, 959-972. http://dx.doi.org/10.2307/2408001

Green, D.S., 1980. The terminal velocity and dispersal of spinning samaras. Am. J. Bot. 67, 1218-1224.

Greene, D.F., Johnson, E.A., 1993. Seed mass and dispersal capacity in wind-dispersed diaspores. Oikos 67, 69-74. http://dx.doi.org/10.2307/3545096

Groth, E., Tandre, K., Engström, P., Vergara-Silva, F., 2011. AGAMOUS subfamily MADS-box genes and the evolution of seed cone morphology in Cupressaceae and Taxodiaceae. Evol. Dev. 13, 159-170, http://dx.doi.org/10.1111/j.1525-142X.2011.00466.x. 
Habrouk, A., Retana, H., Espelta, J.M., 1999. Role of heat tolerance and cone protection of seeds in the response of three pine species to wildfires. Plant Ecol. 145, 91-99. http://dx.doi.org/10.1023/A:1009851614885.

Haines, R.J., 1983. Seed development in Araucaria Juss. Aust. J. Bot. 31, 255-267, http://dx.doi.org/10.1071/BT9830255.

Hamrick, J.L., Murawski, D.A., Nason, J.D., 1993. The influence of seed dispersal mechanisms on the genetic structure of tropical tree populations. Vegetatio 107/108, 281-297. http://dx.doi.org/10.1007/978-94-011-1749-4_20

Hao, D.C., Xiao P.G., Huang, B.L., Ge, G.B., Yang, L., 2008. Interspecific relationships and origins of Taxaceae and Cephalotaxaceae revealed by partitioned Bayesian analyses of chloroplast and nuclear DNA sequences. Plant Syst. Evol. 276, 89-104. http://dx.doi.org/10.1007/s00606-008-0069-0

Harris, T.M., 1943. The fossil conifer Elatides williamsoni. Ann. Bot. 7, 325-339.

Harris, T.M., 1953. Conifers of the Taxodiaceae from the Wealden Formation of Belgium. Mem. Inst. R. Sci. Nat. Belg. 126, 1-43.

Harris, T.M., 1976. The Mesozoic gymnosperms. Rev. Palaeobot. Palynol. 21, 119-134.

Harris, T.M., 1979. The Yorkshire Jurassic flora V. Coniferales. British Museum (Natural History), London, UK.

Hart, J.A., 1987. A cladistics analysis of conifers: preliminary results. J. Arnold. Arbor. 68, 269307.

Herrera, C.M., 1982. Defense of ripe fruit from pests: its significance in relation to plantdisperser interactions. Am. Nat. 120, 218-241.

Herrera, C.M., 1983. Determinants of plant-animal coevolution: the case of mutualistic dispersal 
of seeds by vertebrates. Oikos 44, 132-141. http://dx.doi.org/ 10.2307/3544054

Herrera, C.M., 1985. Habitat-consumer interactions in frugivorous birds, in: Cody, M.L. (Ed.), Habitat Selection in Birds. Academic Press, New York, pp. 341-365.

Herrera, C.M., 1989. Seed dispersal by animals: A role for angiosperm diversification? Am. Nat. $133,309-322$.

Herrera, C.M., Jordano, P., Lopez-Soria, L., Amat, J.A., 1994. Recruitment of a mast-fruiting, bird dispersed tree: bridging frugivore activity and seedling establishment. Ecol. Monogr. 64, 315-344. http://dx.doi.org/10.2307/2937165

Herrera, F., Shi, G., Leslie, A.B., Knopf, P., Ichinnorov, N., Takahashi, M., Crane, P.R., Herendeen, P.S., 2015. A new Voltzian seed cone from the Early Cretaceous of Mongolia and its implications for the systematics of ancient conifers. Int. J. Plant Sci. 176, 791809. http://dxx.doi.org/10.1086/683060

Higgins, S.I., Richardson, D.M., 1999. Predicting plant migration rates in a changing world: the role of long-distance dispersal. Am. Nat. 153, 464-475. http://dx.doi.org/10.1086/303193

Hill, R.S., Brodribb, T.J., 1999. Southern conifers in time and space. Aust. J. Bot. 47, 639-697.

Hill, R.S., Carpenter, R.J., 1991. Evolution of Acmopyle and Dacrycarpus (Podocarpaceae) foliage as inferred from macrofossils in south-eastern Australia. Aust. Syst. Bot. 4, 449479. http://dxx.doi.org/10.1071/SB9910449

Hilton J., Bateman, R.M., 2006. Pteridosperms are the backbone of seed-plant phylogeny. J. Torrey Bot. Soc. 133, 119-168.

Howe, H., 1984. Constraints on the evolution of mutualisms. Am. Nat. 123, 764-777.

Howe H. F., 1986. Seed dispersal by fruit-eating birds and mammals, in: Murray, D.R., (Ed.), Seed Dispersal. Academic Press, Sydney, New South Wales, pp. 123-189. 
Howe, H.F., Mariti, M.N., 2004. When seed dispersal matters. BioScience 54, 651-660. http://dx.doi.org/10.1641/0006-3568(2004)054[0651:WSDM]2.0.CO;2

Howe, H.F., Smallwood, J., 1982. Ecology of seed dispersal. Ann. Rev. Ecol. Syst. 13, 208-228.

Jagel, A., 2001. Morphologische und morphogenetische Untersuchungen zur Systematik und Evolution der Cupressaceae s.l. (Zypressengewächse). Doctoral Thesis, Spezielle Botanik, Ruhr-Univ. Bochum, Germany.

Jordano, P., 1993. Geographic ecology and variation of plant-seed disperser interactions: southern Spanish junipers and frugivorous thrushes. Vegetatio 107/108, 85-104.

Jordano, P., 1994. Spatial and temporal variation in the avian-frugivore assemblage of Prunus mahaleb: patterns and consequences. Oikos 71, 479-491. http://dx.doi.org/10.2307/3545836

Jordano, P., 1995. Angiosperm fleshy fruits and seed dispersers: a comparative analysis of adaptation and constraints in plant-animal interactions. Am. Nat. 145, 163-191.

Jung, W., 1968. Hirmerella münsteri (Schenk) Jung nov. comb. eine bedeustame Konifere des Mesozoikums. Palaeontogr. Abt. B 122, 55-93.

Kelch, D.G., 1997. The phylogeny of the Podocarpaceae based on morphological evidence. Syst. Bot. 22, 113-131.

Kelch, D.G., 1998. Phylogeny of Podocarpaceae: comparison of evidence from morphology and 18S rDNA. Am. J. Bot. 85, 986-996.

Kerp, J.H.F., Poort, R.J., Swinkels, H.A.J.M., Verwer, R., 1990. Aspects of Permian paleobotany and palynology. IX. Conifer-dominated Rotleigend Floras from the Saar-Nahe Basin (?Late Carboniferous-Early Permian; SW-Germany) with special reference to the reproductive biology of early conifers. Rev. Palaeobot. Palynol. 62, 205-248. 
Kirkpatrick, J.B., Bridle, K.L., Dickinson, K.J.M., 2010. Decades-scale vegetation change in burned and unbrned alpine coniferous health. Austr. J. Bot. 58, 453-462.

Klingenberg, C.P., 2008. Morphological integration and developmental modularity. Annu. Rev. Ecol. Evol. Syst. 39, 115-132. http://dx.doi.org/10.1146/annurev.ecolsys.37.091305.110054

Knopf, P., Schulz, C., Little, D.P., Stützel, T., Stevenson, D.W., 2012. Relationships within Podocarpaceae based on DNA sequence, anatomical, morphological, and biogeographical data. Cladistics 28, 271-299. http://dx.doi.org/10.1111/j.1096-0031.2011.00381.x

Krassilov, V.A., 1982. On the ovuliferous organ of Hirmeriella. Phyta 1, 141-144.

Kunzmann, L., 2007. Araucariaceae (Pinopsida): Aspects in palaeobiogeography and palaeobiodiversity in the Mesozoic. Zoologischer Anzeiger 246, 257-277.

Kvaček, Z., 2002. Novelties on Doliostrobus (Doliostrobaceae), an extinct conifer genus of the European Palaeogene. Časopis Národního Muzea 171, 131-175.

Lapasha, C.A., Miller, C.N., 1981. New taxodiaceous seed cones from the upper Cretaceous of New Jersey. Am. J. Bot. 68, 1374-1382.

Lehouck, V., Bonte, D., Spanhove, T., Lens, L., 2012. Integrating context- and stage-dependent effects in studies of frugivorous seed dispersal: an example from south-east Kenya, in: Clobert, J., Baguette, M., Benton, T.G., Bullock, J.M. (Eds.), Dispersal ecology and evolution. Oxford Univ. Press, Oxford, pp. 50-59.

Leishman, M.R., Wright, I.J., Moles, A.T., Westoby, M., 2000. The evolutionary ecology of seed size, in: Fenner, M. (Ed.), Seeds: the ecology of regeneration in plant communities. CAB International, Wallingford, pp. 31-57.

Longton, R.E., 1992. Reproduction and rarity in British mosses. Biol. Conserv. 59, 89-98. 
Leimar, O., Norberg, U., 1997. Metapopulation extinction and genetic variation in dispersalrelated traits. Oikos 80, 448-458. http://dx.doi.org/10.2307/3546617

Leslie, A. B., 2011. Shifting functional roles and the evolution of conifer pollen producing and seed-producing cones. Paleobiology 37, 587-602. http://dx.doi.org/10.1666/10049.1

Leslie, A.B., Beaulieu, J.M., Rai, H.S., Crane, P.R., Donoghue, M.J., Mathews, S., 2012. Hemisphere-scale differences in conifer evolutionary dynamics. Proc. Natl. Acad. Sci. U.S.A. 109, 16217-16221. http://dx.doi.org/10.1073/pnas.1213621109

Leslie, A.B., Beaulieu, J.M., Crane, P.R., Donoghue, M.J., 2013a. Explaining the distribution of breeding and dispersal syndromes in conifers. Proc. R. Soc. B. 280, 20131812. http://dx.doi.org/10.1098/rspb.2013.1812

Leslie, A.B., Beaulieu, J.M., Crane, P.R., Knopf, P., Donoghue, M.J., 2015. Integration and macroevolutionary patterns in the pollination biology of conifers. Evolution 69, 15731583. http://dx.doi.org/10.1111/evo.12670

Leslie, A.B., Glasspool, I., Herendeen, P.S., Ichinnorov, N., Knopf, P., Takahashi, M., Crane, P.R., 2013b. Pinaceae-like reproductive morphology in Schizolepidopsis canicularis sp. nov. from the Early Cretaceous (Aptian-Albian) of Mongolia. Am. J. Bot. 100, 24262436. http://dx.doi.org/10.3732/ajb.1300173

Levin, S.A., Cohen, D., Hastings, A., 1984. Dispersal strategies in patchy environments. Theor. Popul. Biol. 26, 165-191.

Levine, J.M., Murrell, D.J., 2003. The community-level consequences of seed dispersal patterns. Annu. Rev. Ecol. Evol. Syst. 34, 549-574. http://dx.doi.org/10.1146/annurev.ecolsys.34.011802.135400

Lewis, P.O., 2001. A likelihood approach to estimating phylogeny from discrete morphological 
character data. Syst. Biol. 50, 913-925.http://dx.doi.org/10.1080/106351501753462876

Little, D.M., Schwartzbach, A.E., Adams, R.P., Hsieh, C.-F., 2004. The circumscription and phylogenetic relationships of Callitropsis and the newly described genus Xanthocyparis (Cuppressaceae). Am. J. Bot., 1872-1881.

Looy, C.V., Stevenson, R.A., 2014. Earliest occurrence of autorotating seeds in conifers: the mid-Permian (Kungurian-Wordian) Manifera talaris sp. nov. Int. J. Plant Sci. 75, 841854. http://dx.doi.org/ 10.1086/676973

Lord, J.M., 2004. Frugivore gape size and the evolution of fruit size and shape in the southern hemisphere floras. Austral Ecol. 29, 430-436.

Losos, J.B., 2011. Convergence, adaptation, and constraint. Evolution 65-7, 1827-1840. http://dx.doi.org/10.1111/j.1558-5646.2011.01289.x

Mack, A.L., 2000. Did fleshy fruit pulp evolve as a defence against seed loss rather than as a dispersal mechanism?. J. Biosci. 25, 93-97. http://dx.doi.org/10.1007/BF02985186

Maddison, W.P., Fitzjohn, R.G., 2015. The unsolved challenge to phylogenetic correlation tests for categorical characters. Syst. Biol. 64, 127-136. http://dx.doi.org/10.1093/sysbio/syu070

Maddison, W.P., Maddison, D.R., 2011. Mesquite: a modular system for evolutionary analysis. Version 2.75, http://mesquiteproject.org.

Maddison, W.P., Slatkin, M., 1991. Null models for the number of evolutionary steps in a character on a phylogenetic tree. Evolution 45, 1184-1197. http://dx.doi.org/10.2307/2409726

Manchester, S.R., O’Leary, E.L., 2010. Phylogenetic distribution and identification of finwinged fruits. Bot. Rev. 76, 1-82. http://dx.doi.org/10.1007/s12229-010-9041-0 
Manzaneda, A.J., Rey, P.J., Alcántara, J.M., 2009. Conflicting selection on diaspore traits limits the evolutionary potential of seed dispersal by ants. J. Evol. Biol. 22, 1407-1417. http://dx.doi.org/10.1111/j.1420-9101.2009.01752.x

Mao, K., Milne R.I., Zhang, L., Peng, Y., Liu J., Thomas P., Mill, R.R., Renner, S.S., 2012. Distribution of living Cupressaceae reflects the breakup of Pangea. Proc. Natl. Acad. Sci. U.S.A. 109, 7793-7798. http://dx.doi.org/10.1073/pnas.1114319109

Marshall, C.M., 2014. The evolution of morphogenetic fitness landscapes: conceptualising the interplay between the developmental and ecological drivers of morphological innovation. Aust. J. Zool. 62, 3-17. http://dx.doi.org/10.1071/ZO13052

Matlack, G.R., 1987. Diaspore size, shape, and fall behavior in wind-dispersed plant species. Am. J. Bot 74, 1150-1160.

McPeek, M.A., Holt, R.D., 1992. The evolution of dispersal in spatially and temporally varying environments. Am. Nat. 140, 1010-1027.

Meyen, S.V., 1988. Gymnosperms of the Angaran flora, in: Beck, C.B. (Ed.), The origin and evolution of gymnosperms. Columbia Univ. Press, New York, pp. 338-381.

Meyen, SV. 1997. Permian conifers of Western Angaraland. Rev. Palaeobot. Palynol. 96, 351447.

Midford, P., Maddison, W., 2006. Correl package for Mesquite, version 0.1. http://mesquiteproject.org

Mill, R.R., 2003. Towards a biogeography of the Podocarpaceae. Acta Horticulturae 615, 137147.

Mill, R.R., Möller, M., Christie, F., Glidewell, S.M., Masson, D., Williamson, B., 2001. Morphology, anatomy and ontogeny of female cones in Acmopyle pancheri (Brongn. \& 
Gris) Pilg. (Podocarpaceae). Ann. Bot. 88, 55-67.

http://dx.doi.org/10.1006/anbo.2001.1426

Miller, C.N., 1977. Mesozoic conifers. Bot. Rev. 43, 217-280.

Miller, C.N., 1988. The origin of modern conifer families, in: Beck, C.B. (Ed.), Origin and Evolution of Gymnosperms. Columbia Univ. Press, New York, pp. 448-486.

Miller, C.N., 1999. Implications of fossil conifers for the phylogenetic relationships of living families. Bot. Rev. 65, 239-277.

Miller, C.N., Lapasha, C.A., 1983. Structure and Affinities of Athrotaxites berryi Bell, an Early Cretaceous Conifer. Am. J. Bot. 70, 772-779.

Nathan, R., Muller-Landau, H.C., 2000. Spatial patterns of seed dispersal, their determinants, and consequences for recruitment. Trends Ecol. Evol. 15, 278-285.

Ne'eman, G., Goubitz, S., Nathan, R., 2004. Reproductive traits of Pinus halepensis in the light of fire - a critical review. Plant Ecol. 171, 69-79. http://dx.doi.org/10.1023/B:VEGE.0000029380.04821.99

Nogales, M., González-Castro, A., Marrero, P., Bonnaud, E., Traveset, A., 2013. Contrasting selective pressures on seed traits of two congeneric species by their main native guilds of dispersers on islands. PloS ONE 8, e63266. http://dx.doi.org/10.1371/journal.pone.0063266

Norberg, R., 1973. Autorotation, self-stability, and structure of single-winged fruits and seeds (samaras) with comparative remarks on animal flight. Biol. Rev. 48, 561-596.

Novacek, M.J., 1992. Fossils, topologies, missing data, and the higher level phylogeny of eutherian mammals. Syst. Biol. 41, 58-73. http://dx.doi.org/10.1093/sysbio/41.1.58

OED Online, 2015. "fruit, n.". Oxford Univ. Press, Oxford. 
http://www.oed.com/view/Entry/75072?rskey=kJ121M\&result=1 (accessed May 10, 2015).

Omland, K.E., 1999. The assumptions and challenges of ancestral state reconstructions. Syst. Biol. 48, 604-611.

Owens, J.N., Catalano, G.L., Aitken-Christie, J., 1997. The reproductive biology of Kauri (Agathis australis). IV. Late embryogeny, histochemistry, cone and seed morphology. Int. J. Plant Sci. 158, 395-407.

Panti, C., Pujana, R.R., Zamaloa, M.C., Romero, E.J., 2012. Araucariaceae macrofossil record from South America and Antarctica. Alcheringa 36, 1-29. http://dx.doi.org/10.1080/03115518.2011.564562

Pagel, M., 1994. Detecting correlated evolution on phylogenies: a general method for the comparative analysis of discrete characters. Proc. R. Soc. Lond. B 255, 37-45.

Pagel, M., 1999. The maximum likelihood approach to reconstructing ancestral character states of discrete characters on phylogenies. Syst. Biol. 48, 612-622.

Pearce, T., 2011. Convergence and parallelism in evolution: a neo-Gouldian account. Brit. J. Phil. Sci. 0, 1-20. http://dx.doi.org/10.1093/bjps/axr046

Piggin, J., Bruhl, J.J., 2010. Phylogeny reconstruction of Callitris Vent. (Cupressaceae) and its allies leads to inclusion of Actinostrobus within Callitris. Aust. Syst. Bot. 23, 69-93. http://dx.doi.org/10.1071/SB09044

Quinn, C.J., Price, R.A., Gadek, P.A., 2002. Familial concepts and relationships in the conifers based on rbcL and matK sequence comparisons. Kew Bull. 57, 513-531.

Rai, H.S., Reeves, P.A., Peakall, R., Olmstead, R.G., Graham, S.W., 2008. Inference of higherorder conifer relationships from a multi-locus plastid data set. Can. J. Bot. 86, 658-669. 
http://dx.doi.org/10.1139.B08-062

Rao, A.R., 1943. Nipaniostrobus, a new genus of Dacrydium-like seed bearing cones, and other silicified plants from the Rajmahal series. Proc. Natl. Acad. Sci. 13, 113-133.

Restemeyer, J., 2002. Morphologische und morphogenetische Untersuchungen zur Phylogenie und Evolution der Podocarpaceae und Phyllocladaceae. Doctoral Thesis, Spezielle Botanik, Ruhr-Univ. Bochum, Germany.

Ridley, H.N., 1930. The dispersal of plants throughout the world. Reeve and Co., Ashford, UK. Riedl, R., 1978. Order in living organisms: A systems analysis of evolution. Wiley, New York. Ronce, O., Clobert, J., 2012. Dispersal syndromes, in: Clobert, J., Baguette, M., Benton, T.G., Bullock, J.M. (Eds.), Dispersal ecology and evolution. Oxford Univ. Press, Oxford.

Rothwell, G.W., 1988. Cordaitales, in: Beck, C.B. (Ed.), Origin and Evolution of Gymnosperms. Columbia Univ. Press, New York, pp. 273-297.

Rothwell, G.W., Mapes, G., Hernandez-Castillo, G.R., 2005. Hanskerpia gen. nov. and phylogenetic relationships among the most ancient conifers (Voltziales). Taxon 54, 733 750. http://dx.doi.org//10.2307/25065430

Rothwell, G.W., Mapes, G., Stockey, R.A., Hilton, J., 2012. The seed cone Eathiestrobus gen. nov.: fossil evidence for a Jurassic origin of Pinaceae. Am. J. Bot. 99, 708-720. http://dx.doi.org//10.3732/ajb.1100595

Rothwell, G.W., Mapes, G., Stockey, R.A., Hilton, J., Bateman, R.M., 2009. “Descent with modification", transformational series, and phylogenetic analyses to infer the evolution of modern conifer families. Geological Society of America, 2009 annual meeting, Portland, Oregon, USA. Abstracts with Programs 41, 563. [online abstract http://gsa.confex.com/gsa/2009AM/finalprogram/abstract_165301.htm] 
Rothwell, G.W., Stockey, R.A., Mapes, G., Hilton, J., 2011. Structure and relationships of the Jurassic conifer seed cone Hughmillerites juddii gen. et comb. nov.: Implications for the origin and evolution of Cupressaceae. Rev. Palaeobot. Palynol. 164, 45-59. http://dx.doi.org/10.1016/j.revpalbo.2010.11.004

Rubio de Casas, R., Willis, C.G., Donohue, K., 2012. Plant dispersal phenotypes: a seed perspective of maternal habitat selection, in: Clobert, J., Baguette, M., Benton, T.G., Bullock, J.M. (Eds.), Dispersal ecology and evolution. Oxford Univ. Press, Oxford.

Rumeu, B., Afonso, V., Fernández-Palacios, J.M., Nogales, M., 2014. Diversity, distribution and conservation status of island conifers: a global review. Diversity Distrib. 20, 272-283. http://dx.doi.org/10.1111/ddi.12163

Schluter, D., Price, T., Mooers, A.Ø., Ludwig, D., 1997. Likelihood of ancestor states in adaptive radiation. Evolution 51, 1699-1711. http://dx.doi.org/10.2307/2410994

Schulz, C., Jagel, A., Stuitzel, T., 2003. Cone morphology in Juniperus in the light of cone evolution in Cupressaceae s.1.. Flora 198, 161-177.

Schulz, C., Stützel, T., 2007. Evolution of taxodiaceous Cupressaceae (Coniferopsida). Org. Divers. Evol. 7, 124-135. http://dx.doi.org/10.1016/j.ode.2006.03.001

Schupp, E.W., 1995. Conflicts, habitat choice, and patterns of plant recruitment. Am. J. Bot. 82, 399-409.

Schweitzer, H-J., 1963. Der weibliche Zapfen von Pseudovoltzia liebeana und seine Bedeutung für die Phylogenie der Koniferen. Palaeontogr. Abt. B 113, 1-29.

Schweitzer, B.H., 1986. The land flora of the English and German Zechstein sequences, in: Harwood, G.M., Smith, D.B. (Eds.), The English Zechstein and related topics. Blackwell Scientific, Oxford, pp. 31-54. 
Schweitzer, BH. 1996. Voltzia hexagona (Bischoff) Geinitz aus dem Mittleren Perm Westdeutschlands. Palaeontogr. Abt. B. 239, 1-22.

Serbet, R., Escapa, I., Taylor,T., Taylor, E., Cúneo, N.R., 2010. Additional observations on the enigmatic Permian plant Buriadia and implications on early coniferophyte evolution. Rev. Palaeobot. Palynol. 161, 168-178. http://dx.doi.org/10.1016/j.revpalbo.2010.03.011

Shi, G., Leslie, A.B., Herendeen, P.S., Ichinnorov, N., Takahashi, M., Knopf, P., Crane, P.R., 2014. Whole-Plant Reconstruction and Phylogenetic Relationships of Elatides zhoui sp. nov. (Cupressaceae) from the Early Cretaceous of Mongolia. Int. J. Plant Sci. 175, 911930. http://dx.doi.org/10.1086/677651

Sinclair, W.T., Mill, R.R., Gardner, M.F., Woltz, P., Jaffré, T., Preston, J., Hollingsworth, M.L., Ponge, A., Möller, M., 2002. Evolutionary relationships of the New Caledonian heterotrophic conifer, Parasitaxus usta (Podocarpaceae), inferred from chloroplast trnL-F intron/spacer and nuclear rDNAITS2 sequences. Plant Syst. Evol. 233, 79-104. http://dx.doi.org/10.1007/s00606-002-0199-8

Soons, M.B., Bullock, J.M., 2008. Non-random seed abscission, long-distance wind dispersal and plant migration rates. J. Ecol. 96, 581-590. http://dx.doi.org/10.1111/j.13652745.2008.01370.x

Sporne, K.R., 1965. The Morphology of Gymnosperms. Hutchinson University Library, London. Starrfelt, K., Kokko, H., 2012. The theory of dispersal under multiple influences, in: Clobert, J., Baguette, M., Benton, T.G., Bullock, J.M. (Eds.), Dispersal ecology and evolution. Oxford Univ. Press, Oxford, pp. 19-28.

Stefanović , S., Jager, M., Deutsch, J., Broutin, J., Masselot, M., 1998. Phylogenetic relationships of conifers inferred from partial 28S RRNA gene sequences. Am. J. Bot. 85, 
688-697.

Stevenson, R., Evangelista, D., Looy, C.V., 2015. When conifers took flight: a biomechanical evaluation of an imperfect evolutionary takeoff. Paleobiol. 41, 205-225. http://dx.doi.org/10.1017/pab.2014.18

Stewart, W.N., Rothwell, G.W., 1993. Paleobotany and the Evolution of Plants, $2^{\text {nd }}$ ed. Cambridge University Press, UK. Stockey, R.A., 1975. Seeds and embryos of Araucaria mirabilis. Am. J. Bot. 62, 856-868.

Stockey, R.A., 1980. Anatomy and morphology of Araucaria sphaerocarpa Carruthers from the Jurassic Inferior Oolite of Bruton, Somerset. Bot. Gaz. 141, 116-124.

Stockey, R.A., 1982. The Araucariaceae: an evolutionary perspective. Rev. Palaeobot. Palynol. 37, 133-154.

Stockey, R.A., 1994. Mesozoic Araucariaceae: morphology and systematic relationships. J. Plant Res. 107, 493-502. http://dx.doi.org/10.1007/BF02344070

Strauss, S.Y., Irwin, R.E., 2004. Ecological and evolutionary consequences of multispecies plant-animal interactions. Annu. Rev. Ecol. Evol. Syst. 35, 435-466. http://dx.doi.org/10.1146/annurev.ecolsys.35.112202.130215

Stützel, T., Röwekamp, I., 1999. Female reproductive structures in Taxales. Flora 194, 145-157.

Takaso, T., Owens, J.N., 1995. Ovulate cone morphology and pollination in Pseudotsuga and Cedrus. Int. J. Plant. Sci. 156, 630-639.

Takaso, T., Tomlinson, P.B., 1990. Cone and ovule ontogeny in Taxodium and Glyptostrobus (Taxodiaceae-Coniferales). Am. J. Bot. 77, 1209-1221.

Takaso, T., Tomlinson, P.B., 1991. Cone and ovule development in Sciadopitys (TaxodiaceaeConiferales). Am. J. Bot. 78, 417-428. 
Takaso, T., Tomlinson, P.B., 1992. Seed cone and ovule ontogeny in Metasequoia, Sequoia, and Sequoiadendron (Taxodiaceae - Coniferales). Bot. J. Linn. Soc. 109, 15-37. http://dx.doi.org/10.1111/j.1095-8339.1992.tb00256.x

Taylor, E.L., Taylor, T.N., Krings, M., 2009. Paleobotany: the biology and evolution of fossil plants. Academic Press, USA.

Thuiller, W., Albert, C., Araújo, M.B., Berry, P.M., Cabeza, M., Guisan, A., Hickler, T., Midgley, G.F., Paterson, J., Schurr, F.M., Sykes, M.T., Zimmerman, N.E., 2008. Predicting global change impacts on plant species' distributions: future challenges. Perspect. Plant Ecol. Evol. Syst. 9, 137-152. http://dx.doi.org/10.1016/j.ppees.2007.9.004

Tiffney, B.H., 1986a. Evolution of seed dispersal syndromes according to the fossil record, in: Murray, D.R. (Ed.), Seed dispersal. Academic Press, Sydney, New South Wales, pp. 273305.

Tiffney, B.H., 1986b. Fruit and seed dispersal in the Hamamelidae. Ann. Missouri Bot. Gard. 73, 394-416. http://dx.doi.org/10.2307/2399119

Tiffney, B.H., 2004. Vertebrate dispersal of seed plants through time. Annu. Rev. Ecol. Evol. Syst. 35, 1-29. http://dx.doi.org/10.1146/annurev.ecolsys.34.011802.132535

Tiffney, B.H., Mazer, S.J., 1995. Angiosperm growth habit, dispersal and diversification reconsidered. Evol. Ecol. 9, 93-117. http://dx.doi.org/10.1007/BF01237700

Tomback, D.F., Linhart, Y.B., 1990. The evolution of bird-dispersed pines. Evol. Ecol. 4, 185219. http://dx.doi.org/10.1007/BF02214330

Tomlinson, P.B., Braggins, J.E., Rattenbury, J.A., 1991. Pollination drop in relation to cone morphology in Podocarpaceae: a novel reproductive mechanism. Am. J. Bot. 78, 12891303. 
Tomlinson, P.B., 1992. Aspects of cone morphology and development in Podocarpaceae (Coniferales). Int. J. Plant Sci. 153, 572-588.

Tomlinson, P.B., Takaso, T., 2002. Seed cone structure in conifers in relation to development and pollination: a biological approach. Can. J. Bot. 80, 1250-1273. http://dx.doi.org/10.1139/B02-112

Townrow, J.A., 1967a. On Rissikia and Mataia Podocarpaceous conifers from the lower Mesozoic of Southern Lands. Pap. Proc. R. Soc. Tasmania 101, 103-136.

Townrow, J.A., 1967b. On a conifer from the Jurassic of East Antarctica. Pap. Proc. R. Soc. Tasmania 101, 137-146.

Van der Pijl, L. 1982. Principles of dispersal in higher plants, third ed. Springer-Verlag, Berlin, Germany.

Van Valen, L., 1971. Group selection and the evolution of dispersal. Evolution 25, 591-598. http://dx.doi.org/10.2307/2406942

Vander Wall, S.B., 2008. On the relative contributions of wind vs. animals to seed dispersal of four Sierra Nevada pines. Ecology 89(7), 1837-1849. http://dx.doi.org/10.1890/07-0409.1

Vander Wall, S.B., Balda, R.P., 1977. Coadaptations of the Clark's Nutcracker and the Piñon Pine for efficient seed harvest and dispersal. Ecol. Monogr. 47, 89-111. http://dx.doi.org/10.2307/1942225

Vander Wall, S.B., Kuhn, K.M., Beck, M.J., 2005. Seed removal, seed predation, and secondary dispersal. Ecology 86, 801-806. http://dx.doi.org/10.1890/04-0847

Vishnu-Mittre, 1958. Studies on the fossil flora of Nipania (Rajmahal Series), Bihar. Coniferales. Paleobotanist 62, 82-112.

Wake, D.B., Wake, M.H., Specht, C.D., 2011. Homoplasy: from detecting pattern to determining 
process and mechanism of evolution. Science 331, 1032-1035.

http://dx.doi.org/10.1126/science.1188545

Wake, M.H., 1994. The use of unconventional morphological characters in the analysis of systematic patterns and evolutionary processes, in: Grande, L., Riepple, O. (Eds.), Interpreting the Hierarchy of Nature. Academic Press, San Diego, pp. 173-200.

Wang, X.-Q., Tank, D.C., Sang, T., 2002. Phylogeny and divergence times in Pinaceae: evidence from three genomes. Mol. Biol. Evol. 17, 773-781. http://dx.doi.org/10.3724/SP.J.1002.2008.08056

Watson, 1988. The Cheirolepidiaceae, in: Beck, C.B. (Ed.), Origin and Evolution of Gymnosperms. Columbia Univ. Press, New York, pp. 382-447.

Wilf, P., 2012. Rainforest conifers of Eocene Patagonia: attached cones and foliage of the extant Southeast Asian and Australasian genus Dacrycarpus (Podocarpaceae). Am. J. Bot. 99, 562-584. http://dx.doi.org/10.3732/ajb.1100367

Wilkinson, M., 1995. A comparison of two methods of character construction. Cladistics 11, 297-308. http://dx.doi.org/10.1111/j.1096-0031.1995.tb00091.x

Wills, M.A., Fortey, R.A., 2002. The shape of life: how much is written in stone? BioEssays 22, $1142-1152$.

Willson, M.F., Rice, B.L., Westoby, M., 1990. Seed dispersal spectra: a comparison of temperate plant communities. J. Veg. Sci. 1, 547-562. http://dx.doi.org/10.2307/3235789

Willson, M.F., Sabag, C., Figueroa, J., Armessto, J.J., 1996. Frugivory and seed dispersal of Podocarpus nubigena in Chiloé, Chile. Rev. Chil. Hist. Nat. 69, 343-349.

Willson, M.F., Whelan, C.J., 1990. The evolution of fruit color in fleshy-fruited plants. Am. Nat. 136, 790-809. 
Wilson, M.V.H., 1992. Importance for phylogeny of single and multiple stem-group fossil species, with examples from fresh-water fishes. Syst. Biol. 41,

Xiang, X-G., Wang, W., Li, R-Q., Lin, L., Liu, Y., Zhou, Z-K., Li, Z-Y., Chen, Z-D., 2014. Large-scale phylogenetic analyses reveal fagalean diversification promoted by the interplay of diaspores and environments in the Paleogene. Perspect. Plant Ecol. Evol. Syst. 16, 101-110. http://dx.doi.org/10.1016/j.ppees.2014.03.001

Xu, X., Li, R., Dong, C., Wang, Q., Jin, P., Sun, B., 2013. New Schizolepis fossils from the Early Cretaceous in Inner Mongolia, China and its phylogenetic position. Acta Geologica Sinica 87, 1250-1263. http://dx.doi.org/10.1111/1755-6724.12126

Yang, Z-Y., Ran, J-H., Wang, X-Q., 2012. Three genome-based phylogeny of Cupressaceae s.l.: further evidence for the evolution of gymnosperms and southern hemisphere biogeography. Mol. Phylogenet. Evol. 64, 452-470. http://dx.doi.org/10.1016/j.ympev.2012.05.004

Yao, X., Zhou, Z., Zhang, B., 1998. Reconstruction of the Jurassic conifer Sewardiodendron laxum (Taxodiaceae). Am. J. Bot. 85, 1289-1300.

Zhang, J., D’Rozario, A., Yao, J., Wu, Z., Wang, L., 2011. A new species of the extinct genus Schizolepis from the Jurassic Daohugou Flora, Inner Mongolia, China with special reference to the fossil diversity and evolutionary implications. Acta Geologica Sinica 85, 471-481. http://dx.doi.org/10.1111/j.1755-6724.2011.00415.x

Zhou, Z., 1983. Stalagma samara, a new podocarpaceous conifer with monocolpate pollen from the Triassic of Hunan, China. Palaeontogr. Abt. B 185, 56-78. 


\section{CAPTIONS}

Table 1. Classification and description of conifer diaspore functional morphotypes. Types delineated within each morphotype represent major structural differences among taxa of the same morphotype. Composition refers to the structures included in the diaspore. Where seed coat modifications are present, they are indicated in the composition column. Syndromes reflect the primary dispersal vector, abbreviated $\mathrm{A}=$ anemochory, $\mathrm{Z}=$ zoochory, $\mathrm{B}=$ barochory, $\mathrm{H}=$ hydrochory.

Table 2. Characters and states used in ancestral state recontructions of conifer diaspores. Above dashed line: all multistate characters, with diaspore composition coded using compound character states (C). Below dashed line: character states for diaspore composition using reductive coding (R) (see Methods section for further explanation).

Table 3. Number of species for each combination of diaspore functional morphotype, diaspore composition, and seed coat modifications. Functional morphotypes are described in Table 1. Diaspore composition refers to the combination of structures that form the complete diaspore. Note that the epimatium is considered to be a modified ovuliferous scale.

Table 4. Summary statistics for maximum parsimony and maximum likelihood reconstructions for dispersal syndrome, diaspore functional morphotype, seed coat modifications, and diaspore composition using both compound character states (C) and reductive coding (R). *Values for diaspore composition using reductive coding (below dashed line) are given for the whole matrix 
(excluding maximum likelihood), followed by for the individual character reconstructions. $\mathrm{CI}=$ consistency index $; \mathrm{RI}=$ retention index $; \mathrm{RCI}=$ rescaled consistency index $; \mathrm{CI}_{\min }=$ the minimum consistency index possible given the number of character states and their frequency among extant taxa.

Figure 1. Examples of diaspore functional morphotypes in conifers (examples named left to right). A. functionally single-winged, A1: integument-derived wing (type 1), Calocedrus decurrens, Fokiena hodginsii, Agathis australis, A2: ovuliferous scale-derived wing (type 2), Pinus sylvestris, Picea rubens, Larix decidua; B. symmetrical double-winged (type 1), Callitris preissi, Xanthocyparis vietnamiensis, Araucaria heterophylla (type 2); C. multiple-winged, Fitzroya cupressoides; D. baccate fructoid, Juniperus communis (type 1), Taxus baccata (type 3); E. drupe-like fructoid, Cephalotaxis harringtonia (type 3), Prumnopitys ladei (type 1); F. accessory fructoid, Dacrydium cupressinum (type 2), Podocarpus macrocarpa (type 1), Halocarpus bidwillii (type 3); G. aggregate fructoid, Microcachrys tetragona; H. nuxoid, Araucaria araucana; I. plain, Pinus strobiformis, Platycladus orientalis. For detailed morphotype descriptions see Table 1. Diaspores not to scale. Illustrations by Stephanie Ranks.

Figure 2. Ancestral state reconstruction of diaspore functional morphotypes and dispersal syndromes and their distribution across the extant conifer phylogeny of Leslie et al. (2012). A. Maximum parsimony ancestral state reconstructions, using unordered, equally weighted characters for functional morphotypes (42 steps; $\mathrm{CI}=0.190 ; \mathrm{RI}=0.883 ; \mathrm{RCI}=0.168$ ) and dispersal syndromes (26 steps; $\mathrm{CI}=0.115 ; \mathrm{RI}=0.896 ; \mathrm{RCI}=0.103$ ). For visual clarity, tree condensed to show only generic and higher taxonomic levels. Branches colored according to the 
reconstructed ancestral state for functional morphotype. Terminal branch states represent the reconstructed state of the last common ancestor of all extant species in the genus, or the observed state for monospecific genera. Reconstructed changes in dispersal syndrome are indicated with a crossing \symbol. B. Functional morphotype of extant species. Each square represents a species, and groupings of squares represent all species within a genus that were included in the analysis. Species squares are ordered according to the full list of taxa (Table S1). C. Dispersal syndromes of extant taxa. D. Maximum likelihood states for functional morphotype, showing proportional likelihoods for nodes in which none of the morphotypes had a probability $\geq 95 \%(\mathrm{Mk} 1$ est. rate $=$ $5.874 \times 10^{-4} ;-\log$ likelihood $\left.=246.23\right)$. Proportional likelihood pie charts correspond with numbered nodes in A. For all other nodes the morphotype with a probability $\geq 95 \%$ matches the state of the branch shown in A.

Figure 3. Ancestral state reconstructions of diaspore compositions and their distribution across the extant conifer phylogeny of Leslie et al. (2012). A. Ancestral state reconstruction for diaspore composition using reductive character coding (five characters, each with present/absent states). The overall reconstruction is a composite of five separate character state reconstructions for each structure that could be included in the diaspore (37 steps for whole matrix; $\mathrm{CI}=0.135$; $\mathrm{RI}=0.983 ; \mathrm{RCI}=0.133)$. Each colored horizontal bar signifies a structure that was reconstructed by maximum parsimony as present for the branch. Maximum likelihood states are indicated at nodes by colored horizontal bars representing the proportional likelihood that a strucuture was present. Maximum likelihood states are shown only for nodes that were ambiguous by parsimony, or that differed from the parsimony reconstruction by a presence $\geq 5 \%$ or an absence $\geq 95 \%$. For clarity, tree condensed to show only generic and higher taxonomic 
levels. Terminal branch states represent the reconstructed state of the last common ancestor of all extant species in the genus, or the observed state for monospecific genera. B. Distribution of diaspore compositions for extant taxa. Squares represent the species included in the analysis, with colored boxes showing species that have a different diaspore composition than indicated by the generic terminal state in A. Species squares are ordered according to the full list of taxa (Table S1). C. Maximum parsimony ancestral state reconstruction for diaspore composition as a multistate character, using unordered, equally weighted characters $(28$ steps; $\mathrm{CI}=0.250 ; \mathrm{RI}=$ 0.934; RCI $=0.233)$. Character coding consisted of 8 compound character states representing unique combinations of structures that are included in the diaspore (see Methods). States within Cupressaceae (Cu), Taxaceae (Ta), Sciadopitys (Sc), the Agathoid clade (Agathis + Wollemia, Ag), Araucaria (Ar), Pinaceae (Pi), and the cycads (Cy) are the same as shown in A. D. Maximum likelihood ancestral states for $\mathrm{C}$, showing proportional likelihoods for nodes in which none of the states had a probability $\geq 95 \%\left(\mathrm{Mk} 1\right.$ est. rate $=4.089 \times 10^{-4} ;-\log$ likelihood $=$ 185.125).

Figure 4. Ancestral state reconstruction of seed coat modifications and their distribution across the extant conifer phylogeny of Leslie et al. (2012). A. Branches colored according maximum parsimony ancestral state reconstructions, using unordered, equally weighted characters (8 steps; $\mathrm{CI}=0.250 ; \mathrm{RI}=0.938 ; \mathrm{RCI}=0.235)$. Maximum likelihood states are shown as proportional likelihood pie charts for nodes in which the most likely state had a probability $\leq 95 \%$ (Mk1 est. rate $=4.053 \times 10^{-4} ;-\log$ likelihood $\left.=38.171\right)$. For all other nodes the morphotype with a probability $\geq 95 \%$ matches the state inferred from parsimony. For visual clarity, tree condensed to show only generic and higher taxonomic levels. Terminal branch states represent the 
reconstructed state of the last common ancestor of all extant species in the genus, or the observed state for monospecific genera. B. Distribution of seed coat modifications observed for extant species. Each square represents a species, and groupings of squares represent all species within a genus that were included in the analysis. Species squares are ordered according to the full list of taxa (Table S1).

Figure 5. Co-occurrence of changes in dispersal syndrome, diaspore functional morphotype,diaspore composition, and seed coat modifications as reconstructed for nodes within extant conifer families. The total number of changes between the reconstructed ancestral states of consecutive nodes for each character are depicted by the four colored shapes. The degree of overlap between the ellipses (or lack thereof) indicates the frequency of co-occurrence between transitions in character states (or lack thereof). Reconstructed state changes in at least one character occurred for 45 consecutive node pairs.

Figure 6. Diaspore morphotype transition network and relation to dispersal syndromes for the ancestral morphotype reconstruction in Fig. 2. Suprafamilial transitions have been excluded due to uncertainty in their reconstruction and character conflict with the reconstructed states of structural characters. Direction of evolutionary transitions in diaspore morphotypes shown as arrows; the number of transitions is shown in white circles and reflected in the width of each arrow. The bold numbers close to each morphotype circle indicate total number of cases in which the morphotypes of consecutive intrafamilial nodes remain the same (no change). Diaspore morphotypes: $\mathrm{P}(\mathrm{z}), \mathrm{P}(\mathrm{h}), \mathrm{P}(\mathrm{b})$ = zoochorous, hydrochorous, and barochorous plain seeds, respectively; Nux = nuxoids; SW, DW, MW = single-winged, double-winged, and multiple- 
winged diaspores, respectively; $\mathrm{AgF}, \mathrm{DF}, \mathrm{BF}, \mathrm{AdF}$ = aggregate, drupe-like, baccate, and adorned fructoids, respectively. Number and direction of transition events were derived from maximum likelihood reconstruction of ancestral states (see Fig. 2) for the conifer phylogeny of Leslie et al. (2012). In the case of reconstructions in which the proportional likelihood of all potential morphotypes $<0.95$ (less than $3 \%$ of all nodes), the state with the highest likelihood was used. The small number(s) listed with each arrow gives the proportional likelihood for the ancestral state(s) of that transition. Since the likelihood of the new morphotype state is generally 1.00 (because it is observed in extant taxa), it is certain that most of these morphotype transitions have actually occured, however these likelihood values provide a crude measure of confidence that the transition took place from the direction shown and at the specified node in Fig. 2, rather than elsewhere within that lineage. 
Figure 1 Morphotype illustrations
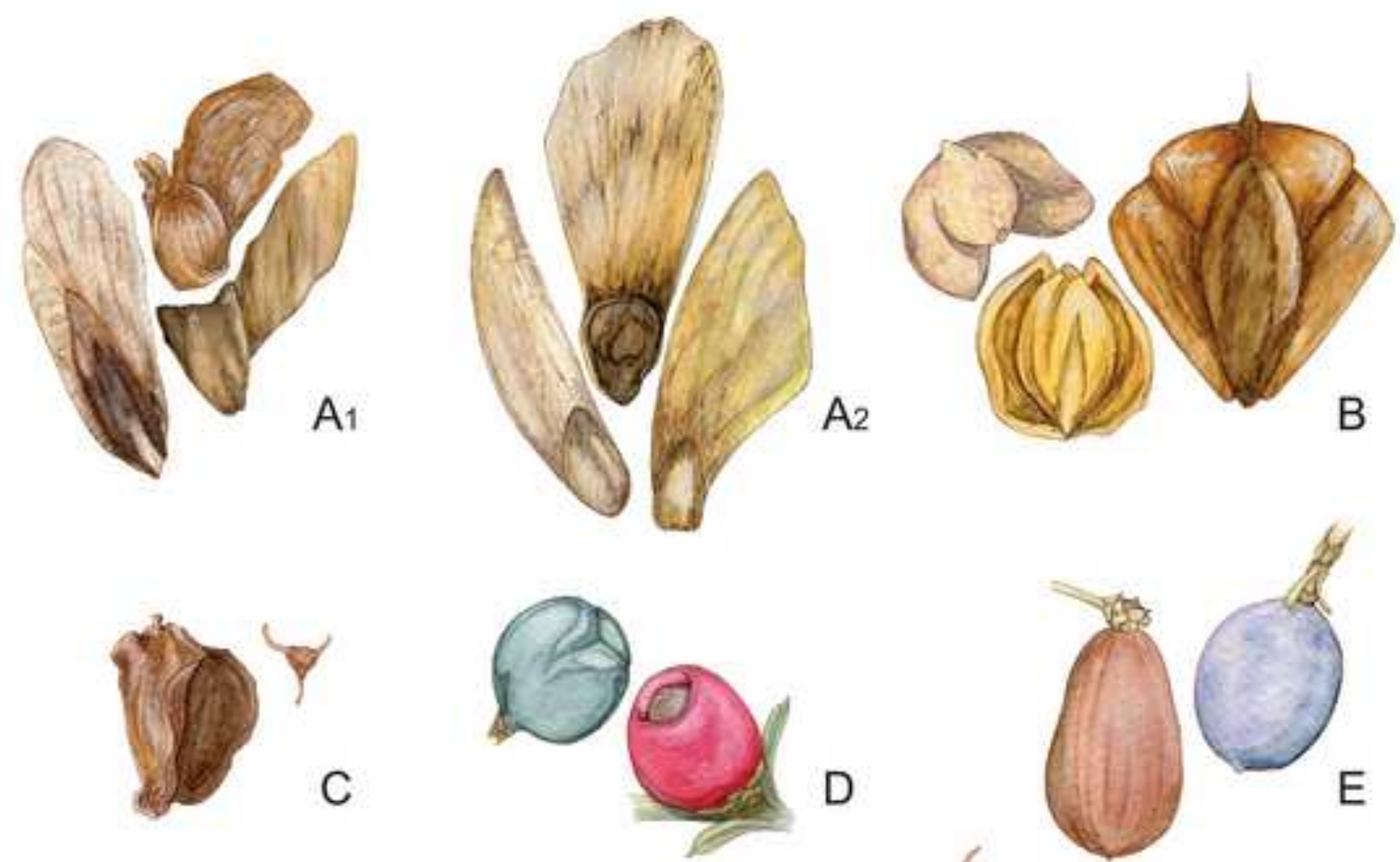

D
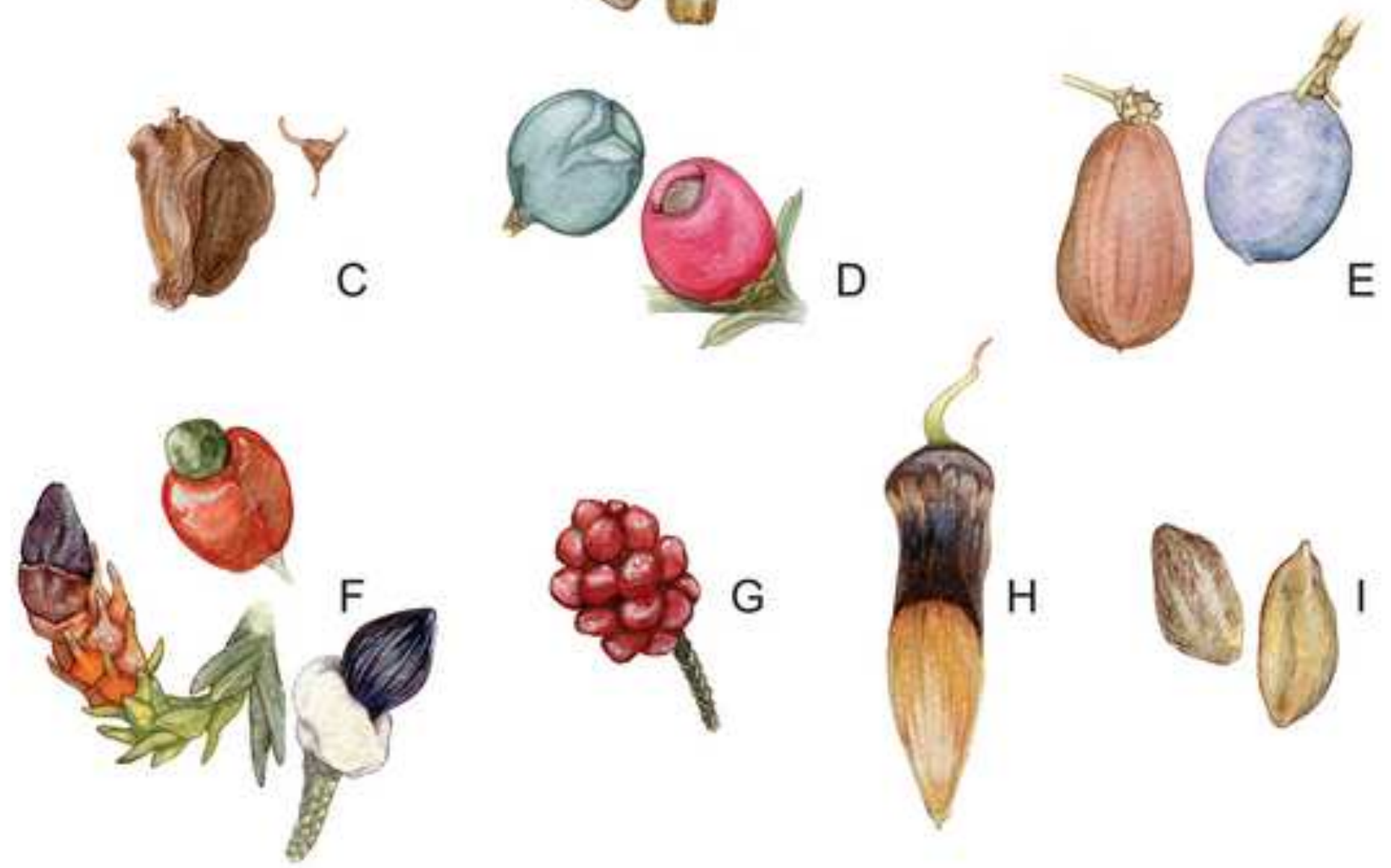


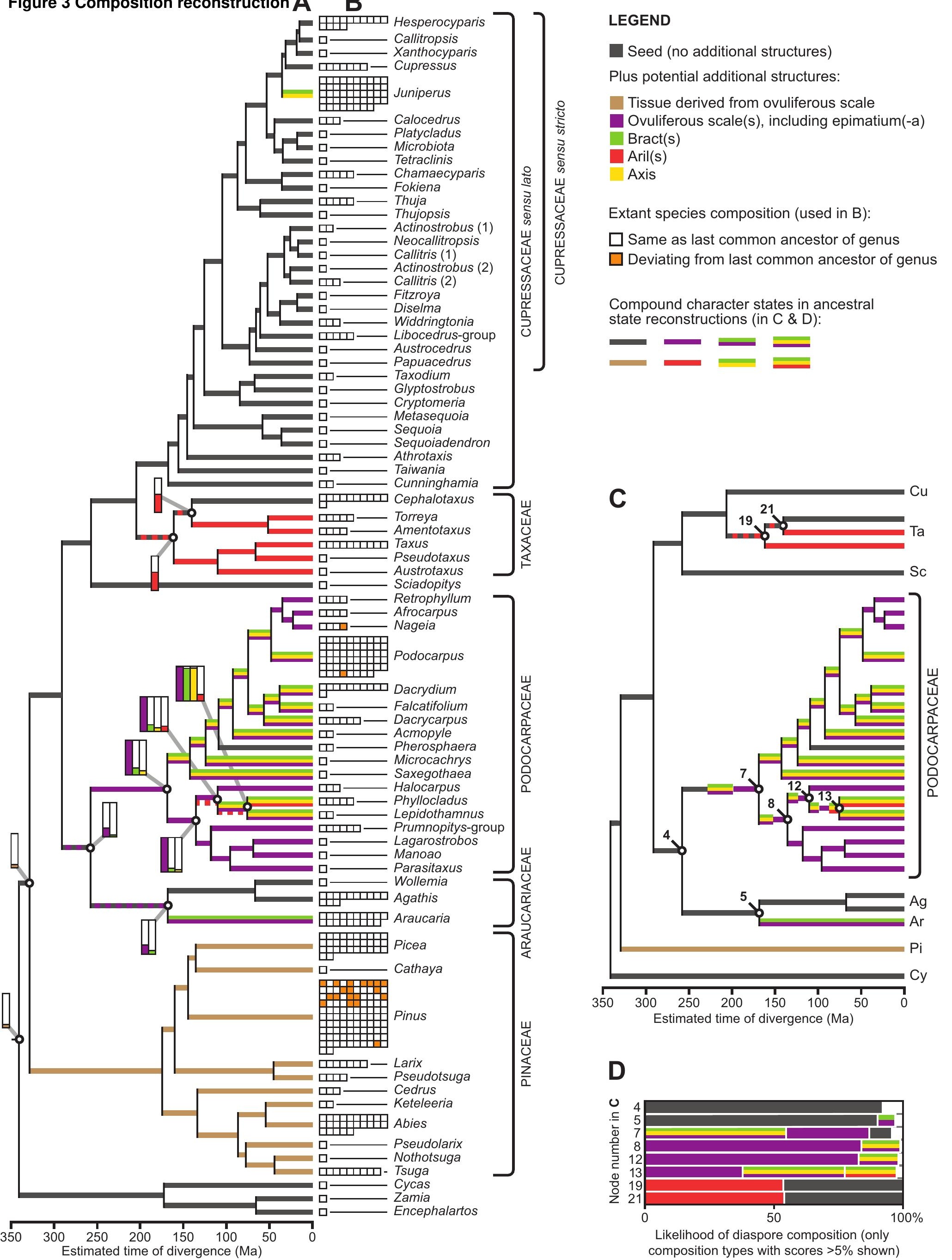

nal structures

Ovuliferous scale(s), including epimatium(-a)

Bract(s)

Aril(s)

Extant species composition (used in B):

$\square$ Same as last common ancestor of genus

Deviating from last common ancestor of genus

Compound character states in ancestral state reconstructions (in $C \&$ D): 
Syndrome changes

23

Morphotype changes

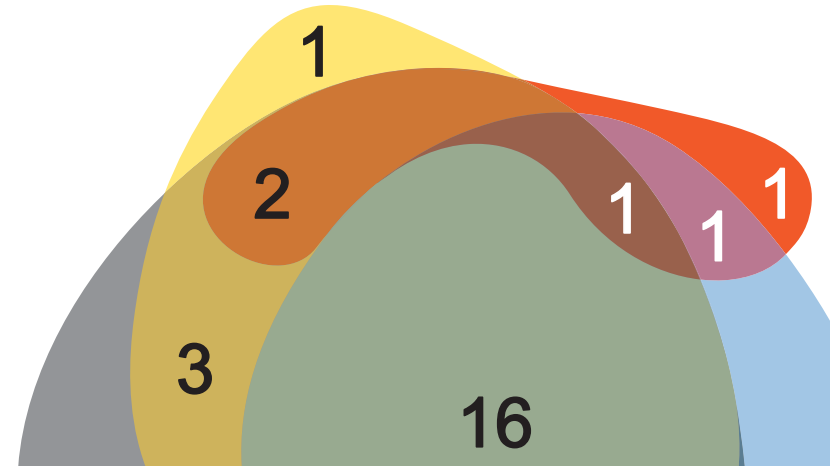

4

- Seed coat 5 changes

\section{Composition} 25 changes

45 Total number of changing nodes 


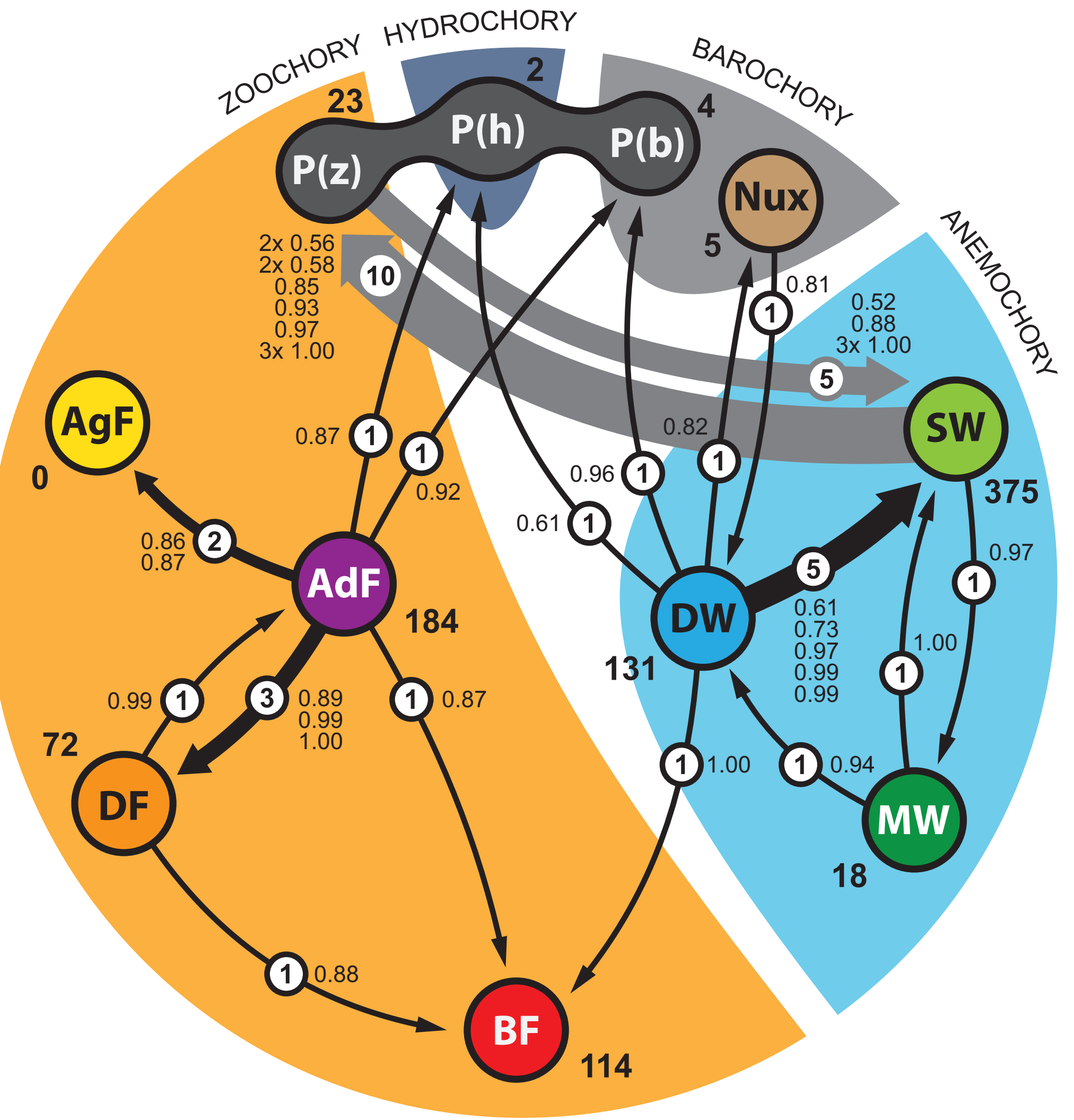


Functionally single-winged - Diaspore with single functional (extended) wing. Autorotating flight.

Type 1: Wings formed by two highly asymmetrical lateral extensions of the integument. The larger wing extended at an oblique angle from either the micropylar end (e.g. Fokienia) or the chalazal end (e.g. Agathis). The smaller wing can be extremely small (rudimentary), fused to larger wing (Calocedrus), or occasionally absent (e.g. Agathis).

Type 2: One wing, formed from tissues of the ovuliferous scale that attach to the seed body during development. Wing extends from the chalazal end of the seed, parallel to the seed axis. Wing attaches either by adhering to the adaxial surface of the seed (e.g. Larix), or by encircling the seed body with a strip of tissue in the same plane as the wing extension.

Double-winged - Diaspore with two roughly symmetrical lateral wings.

Type 1: Wings formed by two lateral extensions of the integument. Width of wings variable, ranging from thin, almost rudimentary strips to extensions equal to or larger in size than the seed body. Wings continuous or discontinuous at either or both the micropylar and chalazal ends. Wings symmetrical or slightly asymmetrical, but not producing a mostly one-winged appearance.

Type 2: Wings formed by thin, papery extensions of the bract-scale complex. Wing size variable between species. Seed embedded in bract-scale complex.

Multiple-winged - Diaspore with three (up to four) wings. Wings formed by lateral extensions of the integument, occurring longitudinally with approximately radial symmetry about the seed's long axis. Wing number variable in some taxa, ranging between 2 to 4 wings. When only two wings, diaspore similar to the symmetrical double wing morphotype.

Baccate fructoid - Diaspore resembles a "berry," formed by reduced cone that is fleshy, colored, relatively round (to ovoid), and short-stalked.

Type 1: Fusion of fertile and sterile bract-scale complexes into one berry-like structure that fully encloses one or more seeds.

Type 2: Single seed fully enclosed in fleshy, colored epimatium. The single, fertile bract not swollen or colored.

Type 3: Open "berry." Single, terminal seed surrounded by an aril leaving only the apex open. Aril fleshy or leathery.

Seed with integumentary wings

Seed + tissue derived from the ovuliferous scale
A

Agathis, Calocedrus,

Callitris macleayana,

Fokienia, Pilgerodendron

A Abies, Pinus spp.
Seed with integumentary

wings

Seed + bract, ovuliferous scale

Seed with integumentary wings
Cupressus spp., Sequoia, Taiwania, Thuja, Wollemia

A Araucaria laubenfelsii,

A. heterophylla

A Actinostrobus arenarius, Callitris endlicheri, Fitzroya, Neocallitropsis

Drupe-like fructoid - Diaspore resembles a drupe, formed by hard seed(s) enclosed by fleshy, colored tissues, often pendulous.

Type 1: Fleshy covering formed by epimatium, surrounding and fusing with seed coat.

Type 2: Fleshy covering formed by aril, surrounding the seed.

Type 3: Fleshy covering formed by outer layer of seed coat (sarcotesta).

Aggregate fructoid - Diaspore resembles a multiple-fruit (e.g. mulberry), formed by entire cone with multiple fertile, fleshy, and colored bract-scale complexes.

Adorned fructoid - Diaspore comprised of seeds displayed by attractive accessory structures that are below or at the base of the seed, and not fully enclosing the seed.

Type 1: Receptacle present, seed fully enclosed by epimatium (fused to integument). Usually one seed per cone.

Type 2: Receptacle present, seed exposed, partially enclosed by epimatium or aril, forming a sheath that is membranous or fleshy around the base of the seed (free from integument). One to several seeds per cone.

Type 3: Receptacle absent, seed partially surrounded at base by epimatium. One or (often) more seeds per cone.

Nuxoid - Diaspore formed by seed enclosed by hard shell, nut-like. Seed embedded in lignified bract-scale complex.

Plain - Diaspore neither winged nor fleshy, no obvious dispersal modifications.

\section{Seed(s) + bracts, axis}

Seed + epimatium

Seed + aril

Z

Juniperus

Z Parasitaxus

Z Pseudotaxus, Taxus

Seed + epimatium

Seed + aril

Z Afrocarpus, Prumnopitys

Z Amentotaxus, Torreya

Z Cephalotaxus

Microcachrys, Saxegothaea epimatium(a)

\begin{tabular}{|c|c|c|}
\hline $\begin{array}{l}\text { Seed(s) + bracts, axis, } \\
\text { epimatium(a) }\end{array}$ & $\mathrm{Z}$ & $\begin{array}{l}\text { Dacrycarpus, Podocarpus, } \\
\text { Acmopyle }\end{array}$ \\
\hline $\begin{array}{l}\text { Seed(s) + bracts, axis, } \\
\text { epimatium(a) or aril(s) }\end{array}$ & $\mathrm{Z}$ & $\begin{array}{l}\text { Dacrydium, Falcatifolium, } \\
\text { Phyllocladus }\end{array}$ \\
\hline Seed + epimatium & $\mathrm{Z}$ & Halocarpus, Manoao \\
\hline $\begin{array}{l}\text { Seed + bract, ovuliferous } \\
\text { scale }\end{array}$ & B & $\begin{array}{l}\text { Araucaria angustifolia, } \\
\text { A. araucana }\end{array}$ \\
\hline Seed, or seed + epimatium & $\mathrm{Z}, \mathrm{B}, \mathrm{H}$ & $\begin{array}{l}\text { Pinus koraiensis, Taxodium, } \\
\text { Microbiota, Lagarostrobus, }\end{array}$ \\
\hline
\end{tabular}


No.

Character

states States

Dispersal syndrome

4 anemochory; zoochory; hydrochory; barochory

Functional morphotype

9 functionally single-winged; double-winged; multiplewinged; baccate fructoid; drupe-like fructoid; aggregate

Seed coat modifications

3 none; wings; fleshy sarcotesta

Diaspore composition (C)

8 seed; seed with tissues derived from ovuliferous scale; seed with whole ovuliferous scale; seed with bract and ovuliferous scale; seed with bracts and axis; seed with bract, axis, and ovuliferous scale; seed with aril; seed with aril, axis, and bracts

\begin{tabular}{|c|c|c|c|}
\hline \multirow{5}{*}{ 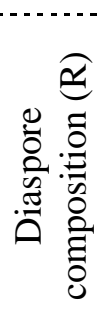 } & Tissues from OS & 2 & absent; present \\
\hline & Ovuliferous scale & 2 & absent; present \\
\hline & Bract & 2 & absent; present \\
\hline & Axis & 2 & absent; present \\
\hline & Aril & 2 & absent; present \\
\hline
\end{tabular}




\section{Table 3}

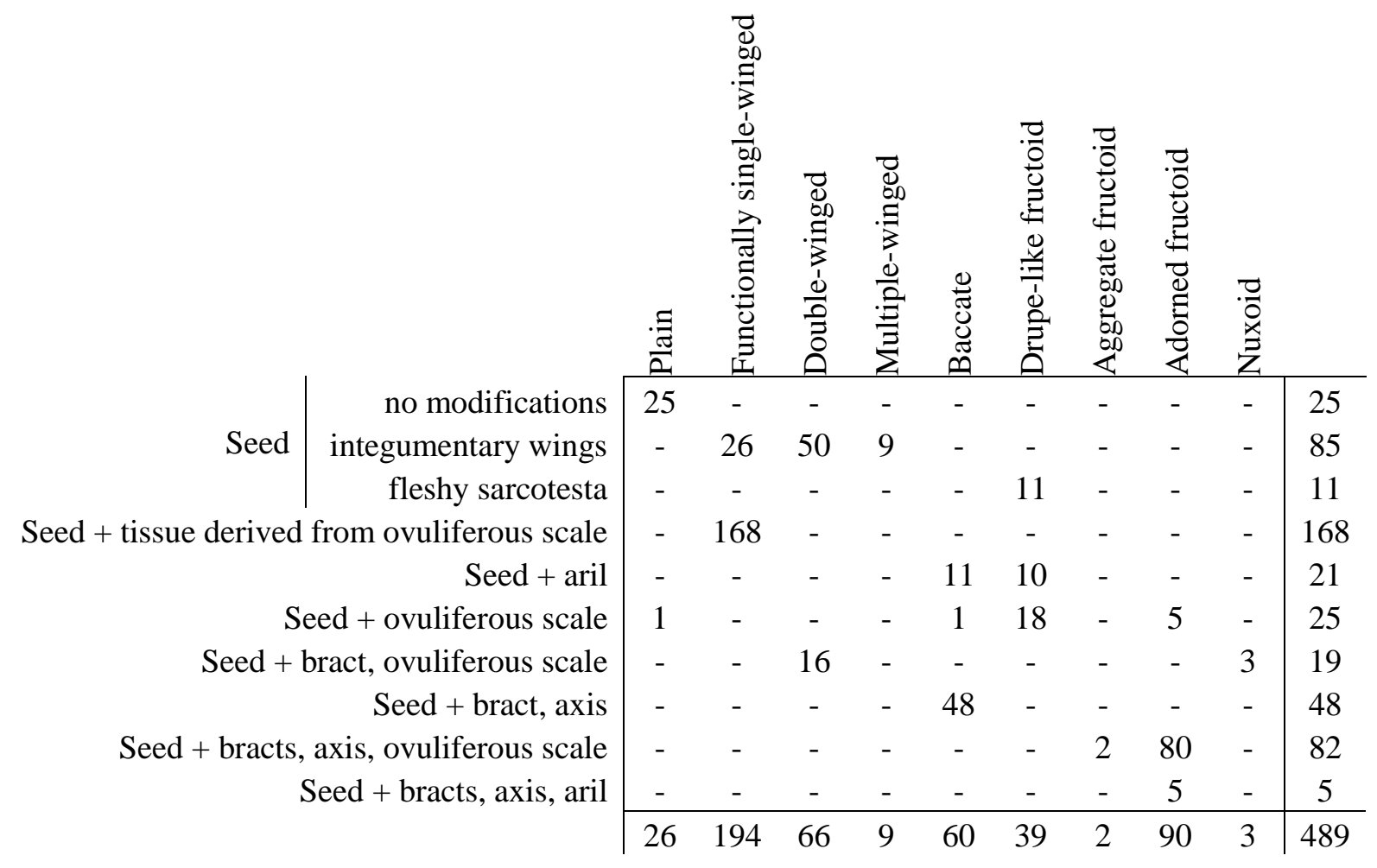




\section{Table 4}

\begin{tabular}{|c|c|c|c|c|c|c|c|c|}
\hline \multirow[b]{2}{*}{ Character } & \multirow[b]{2}{*}{$\begin{array}{c}\text { No. } \\
\text { States }\end{array}$} & \multicolumn{5}{|c|}{ Maximum Parsimony } & \multicolumn{2}{|c|}{ Maximum Likelihood } \\
\hline & & Steps & $C \mathbf{I}_{\min }$ & CI & RI & RCI & Mk1 Rate & $\begin{array}{c}-\log \\
\text { Likelihood } \\
\end{array}$ \\
\hline Syndrome & 4 & 26 & 0.0136 & 0.1154 & 0.8955 & 0.1033 & $9.243 \times 10^{-4}$ & 157.100 \\
\hline Morphotype & 9 & 42 & 0.0271 & 0.1904 & 0.8828 & 0.1681 & $5.874 \times 10^{-4}$ & 246.225 \\
\hline Seed coat & 3 & 8 & 0.0051 & 0.2500 & 0.9381 & 0.2345 & $4.053 \times 10^{-4}$ & 38.171 \\
\hline Composition(C) & 8 & 28 & 0.0218 & 0.2500 & 0.9338 & 0.2334 & $4.089 \times 10^{-4}$ & 185.125 \\
\hline $\operatorname{Composition}(\mathbf{R})^{*}$ & 10 & 37 & 0.0027 & 0.1351 & 0.9825 & 0.1327 & - & - \\
\hline Tissues from $O S$ & 2 & 16 & 0.0031 & 0.0625 & 0.9102 & 0.0569 & $1.718 \times 10^{-3}$ & 101.856 \\
\hline$O S$ & 2 & 4 & 0.0028 & 0.2500 & 0.9760 & 0.2440 & $3.916 \times 10^{-4}$ & 17.836 \\
\hline Aril & 2 & 4 & 0.0022 & 0.2500 & 0.8927 & 0.2232 & $3.909 \times 10^{-4}$ & 18.048 \\
\hline Bract & 2 & 7 & 0.0030 & 0.1429 & 0.9613 & 0.1373 & $7.415 \times 10^{-4}$ & 34.553 \\
\hline Axis & 2 & 6 & 0.0028 & 0.1667 & 0.9632 & 0.1605 & $6.228 \times 10^{-4}$ & 32.068 \\
\hline
\end{tabular}

